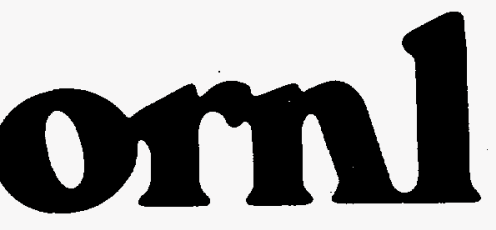

OAK RIDGE NATIONAL LABORATORY

MARTIN MARIETTA
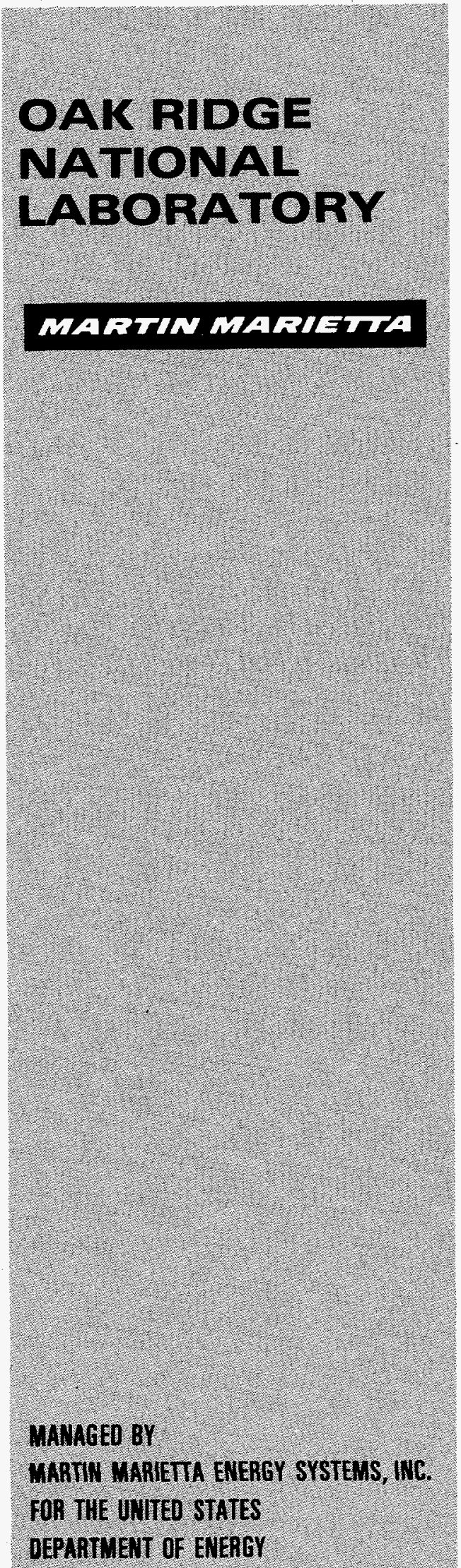

MARTIW MARIETTA ENERGY SYSTEMS, INC. FOh THE UNTEO STATES DEPARTIENT OF ENERG
FEB 271956

OSTI

\section{Flow Blockage Analysis for the Advanced Neutron Source Reactor}

\author{
T. K. Stovall \\ J. A. Crabtree \\ D. K. Felde \\ J. E. Park
}

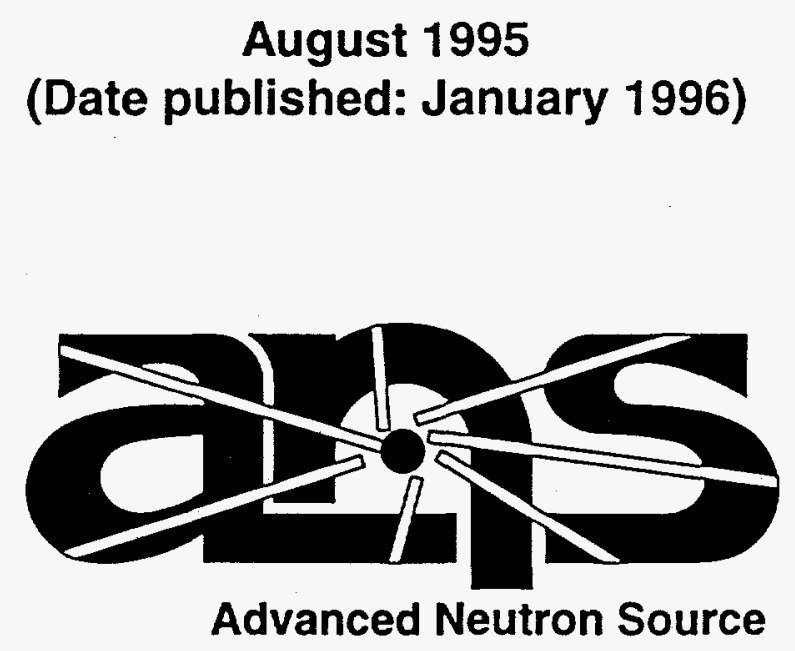

MASTER 
This report has been reproduced directly from the best available copy.

Available to DOE and DOE contractors from the Office of Scientific and Technical Information, P.O. Box 62, Oak Ridge, TN 37831; prices available from (615) 576-8401, FTS 626-8401.

Available to the public from the National Technical Information Service, U.S. Department of Commerce, 5285 Port Royal Rd., Springfield, VA 22161.

This report was prepared as an account of work sponsored by an agency of the United States Government. Neither the United States Government nor any agency thereot, nor any of their employees, makes any warranty, express or implied, or assumes any legal liability or responsibility for the accuracy, completeness, or usefulness of any information, apparatus, product, or process disclosed, or represents that its use would not infringe privately owned rights. Reference herein to any specific commercial product, process, or service by trade name, trademark, manufacturer, or otherwise, does not necessarily constitute or imply its endorsement, recommendation, or favoring by the United States Government or any agency thereof. The views and opinions of authors expressed herein do not necessarily state or reflect those of the United States Government or any agency thereof. 
February 13, 1996

Distribution

Corrected copy of ORNL-6860, Flow Blockage Analysis for the Advanced Neutron Source Reactor

The above-referenced report, authored by T. K. Stovall, J.A. Crabtree, D. K. Felde, and J. E. Park, was distributed two weeks ago and was missing figures for Sect. 8, pps. 8-2 through 8-4. A corrected copy is attached. Please recycle your first copy.

The ANS publications office apologizes for any inconvenience this oversight may have caused.

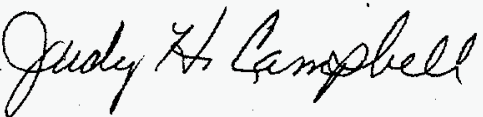

Judy H. Campbell

FEDC, MS8218 


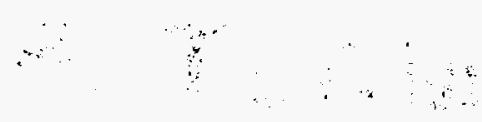

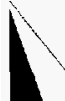

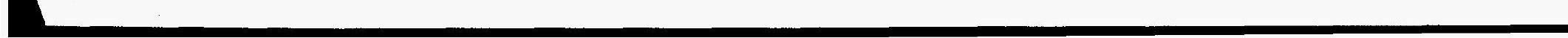


ORNL-6860

FLOW BLOCKAGE ANALYSIS FOR THE ADVANCED NEUTRON SOURCE REACTOR

T. K. Stovall

J. A. Crabtree

D. K. Felde

J. E. Park

August 1995

(Date published: January 1996)

Prepared by the

OAK RIDGE NATIONAL LABORATORY

Oak Ridge, Tennessee 37831

managed by

LOCKHEED MARTIN ENERGY RESEARCH CORP.

for the

U.S. DEPARTMENT OF ENERGY

under contract DE-AC05-96OR22464 


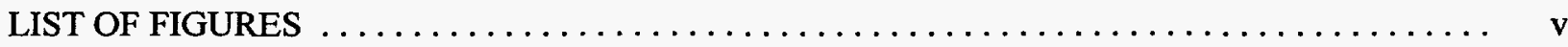

ACRONYMS AND SYMBOLS $\ldots \ldots \ldots \ldots \ldots \ldots \ldots \ldots \ldots \ldots \ldots \ldots \ldots \ldots \ldots \ldots \ldots \ldots$

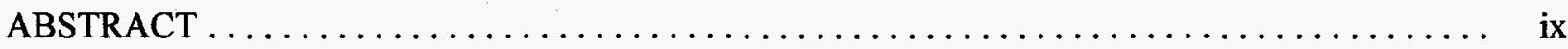

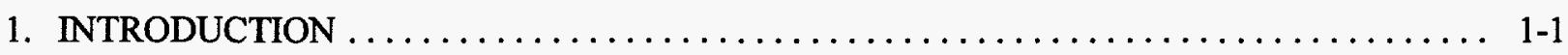

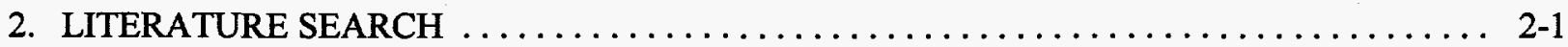

3. EXPERIMENTAL FACILITY DESCRIPTION $\ldots \ldots \ldots \ldots \ldots \ldots \ldots \ldots \ldots \ldots \ldots \ldots \ldots \ldots \ldots \ldots$

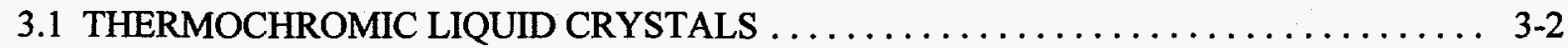

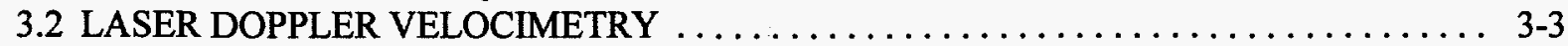

4. NUMERICAL MODELS $\ldots \ldots \ldots \ldots \ldots \ldots \ldots \ldots \ldots \ldots \ldots \ldots \ldots \ldots \ldots \ldots$. $\ldots \ldots \ldots$

4.1 BACKGROUND-MODELING THE SPARROW AND CUR EXPERIMENT . . . . . . 4-1

4.2 FLOW-3D MODELS FOR THE FLOW BLOCKAGE TEST FACILITY GEOMETRY $\ldots$. . 4-2

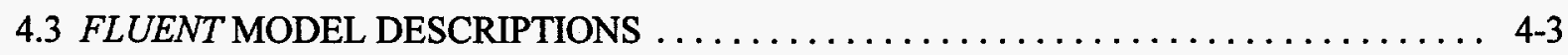

5. EXPERIMENTAL DATA ANALYSIS $\ldots \ldots \ldots \ldots \ldots \ldots \ldots \ldots \ldots \ldots \ldots \ldots \ldots \ldots \ldots \ldots$

5.1 THERMOCHROMIC LIQUID CRYSTAL EXPERIMENTS $\ldots \ldots \ldots \ldots \ldots \ldots \ldots \ldots \ldots-1$

5.2 LASER DOPPLER VELOCIMETRY EXPERIMENTS $\ldots \ldots \ldots \ldots \ldots \ldots \ldots \ldots \ldots .3$

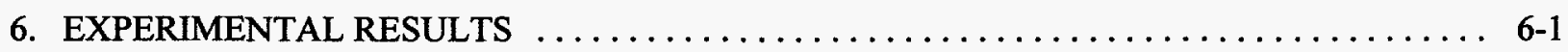

7. COMPARISON OF NUMERICAL MODELS WITH EXPERIMENTAL RESULTS $\ldots \ldots \ldots$ 7-1

8. EXTENSION OF NUMERICAL MODELS TO ADVANCED NEUTRON SOURCE OPERATING CONDITIONS $\ldots \ldots \ldots \ldots \ldots \ldots \ldots \ldots \ldots \ldots \ldots \ldots \ldots \ldots \ldots \ldots \ldots \ldots \ldots \ldots$

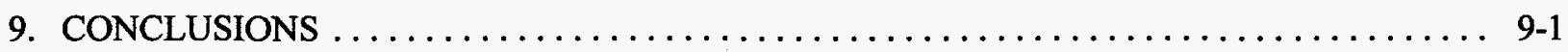

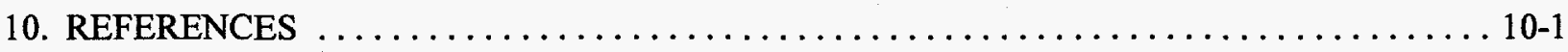




\section{LIST OF FIGURES}

Figure

$\underline{\text { Page }}$

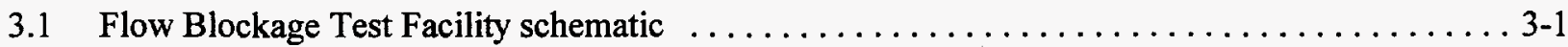

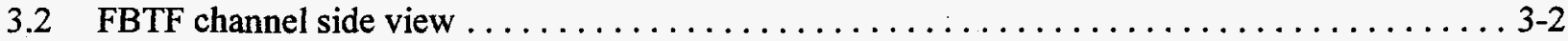

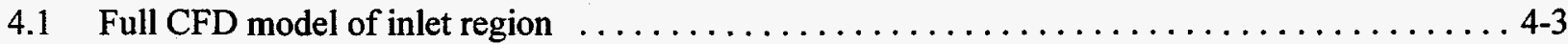

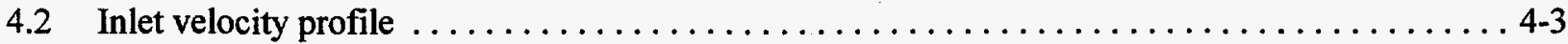

4.3 Numerical model geometry at the channel inlet $\ldots \ldots \ldots \ldots \ldots \ldots \ldots \ldots \ldots \ldots \ldots \ldots$

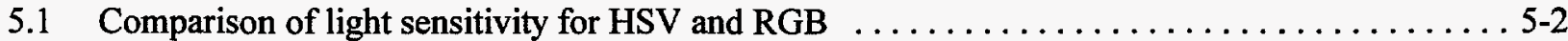

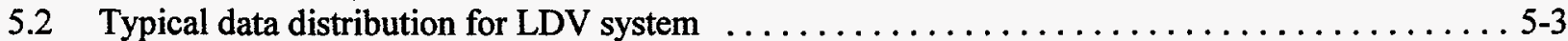

6.1 TLC field temperature with $25 \%$ edge blockage at $\operatorname{Re}=79,000 \ldots \ldots \ldots \ldots \ldots \ldots \ldots 6.2$

6.2 TLC field temperature with $35 \%$ center blockage at $\operatorname{Re}=75,000 \ldots \ldots \ldots \ldots \ldots \ldots \ldots 6.2$

6.3 Axial velocity profiles with $25 \%$ edge blockage at $R e=85,000 \ldots \ldots \ldots \ldots \ldots \ldots \ldots .3$

6.4 Spanwise velocity profiles with $25 \%$ edge blockage at $\operatorname{Re}=85,000 \ldots \ldots \ldots \ldots \ldots \ldots 6.3$

6.5 Turbulent kinetic energy with $25 \%$ edge blockage at $\operatorname{Re}=85,000$ and $x / d_{h}=10.8 \ldots \ldots \ldots 6-5$

6.6 Turbulent kinetic energy with $25 \%$ edge blockage at $R e=85,000$ and $x / d_{b}=23.2 \ldots \ldots \ldots 6-5$

6.7 Turbulent kinetic energy with $25 \%$ edge blockage at $R e=85,000$ and $x / d_{b}=36 \ldots \ldots \ldots 6$

6.8 Axial velocity profiles with $35 \%$ center blockage at $\operatorname{Re}=35,000$ and $81,000 \ldots \ldots \ldots \ldots 6$

6.9 Spanwise velocity profiles with $35 \%$ center blockage at $\operatorname{Re}=35,000$ and $76,000 \ldots \ldots \ldots 6-7$

6.10 Turbulent kinetic energy with $35 \%$ center blockage at $\operatorname{Re}=85,000 \ldots \ldots \ldots \ldots \ldots \ldots 6$

7.1 Comparison of experimental results with CFD predictions for axial velocity profiles

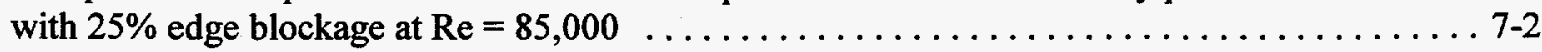

7.2 Comparison of experimental results with CFD predictions for kinetic energy with $25 \%$

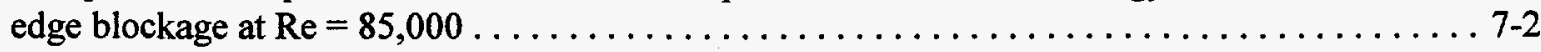

7.3 Comparison of experimental results with CFD predictionsfor axial velocity with $35 \%$

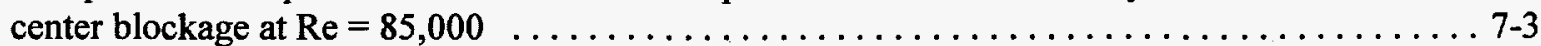

8.1 "Worst-case" heat flux (in $\mathrm{W} / \mathrm{m}^{2}$ ) imposed on channel wall $\ldots \ldots \ldots \ldots \ldots \ldots \ldots \ldots \ldots$.

8.2 Wall temperature (in $\mathrm{K}$ ) for "worst-case" heat flux with $50-\mathrm{mm}$ unheated entrance

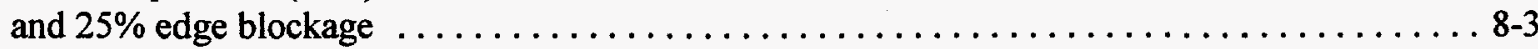

8.3 Velocity vectors (in $\mathrm{m} / \mathrm{s}$ ) for "worst-case" heat flux with $50-\mathrm{mm}$ unheated entrance and $25 \%$ edge blockage 


\section{ACRONYMS AND SYMBOLS}

\begin{tabular}{|c|c|}
\hline$A$ & area \\
\hline ANS & Advanced Neutron Source \\
\hline CFD & computational fluid dynamics \\
\hline$c_{p}$ & specific heat \\
\hline$d_{h}$ & $\begin{array}{l}\text { hydraulic diameter, four times the cross-sectional area divided by the wetted perimeter } \\
(2.50 \mathrm{~mm})\end{array}$ \\
\hline FBTF & Flow Blockage Test Facility \\
\hline$h$ & convective heat transfer coefficient \\
\hline HSV & hue, saturation, and value \\
\hline$I$ & electrical current to heater \\
\hline$k_{\text {heater }}$ & heater conductivity $\left[14 \mathrm{~W} /\left(\mathrm{m} \cdot{ }^{\circ} \mathrm{C}\right)\right]$ \\
\hline & turbulent kinetic energy, in $\mathrm{m}^{2} / \mathrm{s}^{2}$ \\
\hline$L$ & channel length \\
\hline$L_{\text {heater }}$ & heater length \\
\hline LDV & laser doppler velocimeter \\
\hline LUT & lookup table \\
\hline MIT & Massachusetts Institute of Technology \\
\hline$N u$ & Nusselt number \\
\hline $\operatorname{Pr}$ & Prandtl number \\
\hline$q^{\prime \prime}$ & heat flux \\
\hline$R$ & heater electrical resistance \\
\hline $\operatorname{Re}$ & Reynolds number \\
\hline RNG & renormalized group \\
\hline RGB & red-green-blue \\
\hline RSM & Reynolds Stress Model \\
\hline$S$ & channel span (84 mm) \\
\hline Sc & Schmidt number \\
\hline Sh & Sherwood number \\
\hline$t$ & thickness of heater plate $(1 \mathrm{~mm})$ \\
\hline$T$ & temperature \\
\hline$T_{\text {bulk }}$ & fluid bulk temperature \\
\hline$T_{\text {crystal }}$ & temperature recorded by TLC field \\
\hline$T_{\text {wall }}$ & wall temperature facing fluid flow \\
\hline TLC & thermochromic liquid crystals \\
\hline$u$ & velocity \\
\hline$U_{o}$ & average exit fluid flow rate (volumetric flow rate divided by channel cross-sectional area) \\
\hline$u_{i}$ & velocity vector at a point \\
\hline$\overline{u_{i}}$ & time-averaged velocity \\
\hline$u_{i}^{\prime}$ & fluctuating velocity component (velocity perturbation) \\
\hline$w$ & heater width \\
\hline$x$ & axial position \\
\hline $\mathrm{y}^{+}$ & position relative to boundary layer thickness \\
\hline$\rho$ & density \\
\hline
\end{tabular}




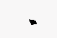




\begin{abstract}
The Advanced Neutron Source (ANS) reactor was designed to provide a research tool with capabilities beyond those of any existing reactors. One portion of its state-of-the-art design required highspeed fluid flow through narrow channels between the fuel plates in the core. Experience with previous reactors has shown that fuel plate damage can occur when debris becomes lodged at the entrance to these channels. Such debris disrupts the fluid flow to the plate surfaces and can prevent adequate cooling of the fuel. Preliminary ANS designs addressed this issue by providing an unheated entrance length for each fuel plate so that any flow disruption would recover, thus providing adequate heat removal from the downstream, heated portions of the fuel plates.

As part of the safety analysis, the adequacy of this unheated entrance length was assessed using both analytical models and experimental measurements. The Flow Blockage Test Facility (FBTF) was designed and built to conduct experiments in an environment closely matching the ANS channel geometry. The FBTF permitted careful measurements of both heat transfer and hydraulic parameters. In addition to these experimental efforts, a thin, rectangular channel was modeled using the Fluent computational fluid dynamics computer code. The numerical results were compared with the experimental data to benchmark the hydrodynamics of the model. After this comparison, the model was extended to include those elements of the safety analysis that were difficult to measure experimentally. These elements included the high wall heat flux pattern and variable fluid properties. The results were used to determine the relationship between potential blockage sizes and the unheated entrance length required.
\end{abstract}




\section{INTRODUCTION}

The Advanced Neutron Source (ANS) reactor is designed to provide a research tool with capabilities beyond those of any existing reactor. One portion of its state-of-the-art design requires high-speed $(25-\mathrm{m} / \mathrm{s})$ fluid flow through a large number of very narrow channels between fuel plates. Each channel is $1.27 \times 84 \times 500 \mathrm{~mm}$. These fuel plates produce a very high heat flux, averaging $6 \mathrm{MW} / \mathrm{m}^{2}$. All precautions must be taken therefore to prevent any disruption to the fluid flow used to remove this heat and to maintain the fuel plates at a safe temperature. Experience with previous reactors has shown that fuel plate damage can occur when debris becomes lodged at the entrance to the channels between plates. Such debris can disrupt the fluid flow to the plate surfaces and prevent adequate cooling of the fuel. Preliminary ANS designs addressed this issue by providing an unheated entrance length for each fuel plate where any flow disruption would recover, thus providing adequate heat transfer for the downstream, heated portions of the fuel plates.

As a part of the safety analysis, the adequacy of this unheated entrance length must be assessed. This evaluation is based on (1) an examination of available data, (2) analytical modeling of the ANS fuel plate geometry, and (3) experimental efforts designed to mimic the ANS fuel plate geometry. Results of this ongoing investigation will be used to refine the ANS design. 


\section{LITERATURE SEARCH}

An extensive literature search was made to find pertinent data describing the behavior of high-speed fluid flow within a partially blocked, thin, rectangular channel. A wealth of information was available for round pipes and open weirs, none of which was appropriate for describing fluid flow in a narrow channel with an aspect ratio of 1/66. Only one experiment was found similar to ANS conditions. Sparrow and Cur performed a detailed mass transfer experiment for a rectangular channel with $25 \%$ and $50 \%$ edge blockages at the entrance. ${ }^{1,2}$ Their data show a very long recirculation region behind the blockage, with greatly reduced mass transfer coefficients in this region.

The Sparrow and Cur experiment used air as the working fluid and had a maximum Reynolds number of 30,000 . Their channel was $4.45 \mathrm{~mm}$ tall by $81.3 \mathrm{~mm}$ wide by $185 \mathrm{~mm}$ long, for an aspect ratio of $1 / 18$ and an equivalent hydraulic diameter of $8.43 \mathrm{~mm}$. Mass transfer rates were evaluated by measuring the change in thickness of a naphthalene wall coating with an accuracy of $\pm 5 \%$. In addition to the 25 and $50 \%$ edge blockage cases, the mass transfer rates for an unblocked channel were also measured. The experimental results are presented as a map of local Sherwood numbers on the wall of the channel as well as spanwise average Sherwood numbers and pressures. The translation from mass transfer to heat transfer. results was based on the following relations for heat transfer from Dittus and Boelter [Eq. (1)] and mass transfer from Gilliland [Eq. (2)]. ${ }^{3}$

$$
\begin{aligned}
& N u_{d}=0.023 \times R e_{d}^{0.8} \times \operatorname{Pr}^{0.4}, \\
& S h_{d}=0.023 \times R e_{d}^{0.8} \times S c^{0.4},
\end{aligned}
$$

where

$N u_{d}=$ Nusselt number,

$R e_{d}=$ Reynolds number,

$\operatorname{Pr}=$ Prandtl number,

$S h_{d}=$ Sherwood number,

$S c=$ Schmidt number.

The goal was use Sparrow and Cur's data to produce a rough, order-of-magnitude projection of the flow behavior within an ANS channel. In addition, because of the many approximations involved (including fluid properties, wall heat flux, fluid velocity, channel geometry, etc.), conservative assumptions were used whenever possible. For example, it was assumed that three adjacent channels were blocked, so that there would be an adiabatic boundary condition on the back side of the fuel plate. This assumption and others described in this section were used with the goal of producing a worst-case estimate of wall heat transfer within the ANS channel under edge blockage conditions.

A number of approximations were used in applying Cur's experimental data to the ANS geometry and hydraulic parameters. The first approximation was based on the relatively constant concentration of the naphthalene in the air flowing through Cur's test section. That constant concentration, inferred by Sparrow based on the very small overall concentration and the negligible change in concentration between the inlet and outlet of the test section, implies that the fluid's properties were constant throughout the test section. For constant properties, the velocity is directly proportional to the Reynolds number. 
From Eq. (2), again for constant fluid properties, the Reynolds number raised to the 0.8 power will be proportional to the Sherwood number. Therefore, the measured mass transfer coefficients, or Sherwood numbers, can be used to represent the velocity field, as shown in Eq. (3). From mass conservation, the spanwise average velocity must be constant. This first approximation therefore used the ratio of local to spanwise-average Sherwood numbers to extrapolate local fluid velocities from the unobstructed ANS flow rate of $27.4 \mathrm{~m} / \mathrm{s}$ (the more recent design specifies $25 \mathrm{~m} / \mathrm{s}$ ), as shown in Eqs. (3) and (4).

$$
\begin{aligned}
& \frac{u_{\text {local }}}{u_{\text {avg }}} \propto \frac{R e_{\text {local }}}{R e_{\text {avg }}} \propto\left(\frac{S h_{\text {local }}}{S h_{\text {avg }}}\right)^{0.8} \\
& u_{\text {local }}=27.4 \mathrm{~m} / \mathrm{s} \times\left(\frac{S h_{\text {local }}}{S h_{\text {avg }}}\right)^{0.8}
\end{aligned}
$$

where

$$
\begin{aligned}
& u=\text { velocity, } \\
& R e=\text { Reynolds number, } \\
& S h=\text { Sherwood number. }
\end{aligned}
$$

Second, the local fluid temperature was increased in the direction of the flow, with an adjustment made for reduced velocity (but not backflows) behind flow blockages. (In Cur's experiment the fluid concentration, analogous to the fluid temperature in the ANS application, was nearly constant.) The highest temperature at each axial position was used as the basis for the next downstream position.

$$
T_{\text {local }}=T_{\text {upstream,max }}+\frac{q^{\prime \prime}{ }_{\text {wall }} \times A_{\text {wall }}}{c_{p} \times \rho \times u_{\text {local }} \times A_{\text {cross-section }}},
$$

where

$$
\begin{aligned}
& T=\text { temperature, } \\
& q^{\prime \prime}=\text { heat flux, } \\
& A=\text { area, } \\
& c_{p}=\text { specific heat, } \\
& \rho=\text { density, and } \\
& u=\text { velocity. }
\end{aligned}
$$

The wall area, $A_{\text {wall }}$, is the incremental area between measurement stations in the direction of the flow. This approximation caused only a slight elevation in the estimated exit temperature above the design exit temperature of $83^{\circ} \mathrm{C}$.

Third, all $\mathrm{D}_{2} \mathrm{O}$ fluid properties except viscosity were calculated for each position based on the temperature of the last upstream temperature, using the $\mathrm{D}_{2} \mathrm{O}$ property relations from ref. 4 . These properties tend to vary only slightly over the length of the channel. Because the viscosity varies strongly with temperature, it was calculated for the estimated temperature of each local position. These local fluid velocities and temperatures were then used to calculate a local Reynolds number. The Prandtl number was also estimated using these temperature-dependent properties. This local Reynolds number [already based 
on velocities extrapolated from the empirical data as shown by Eq. (3)] was then used to extrapolate a local Nusselt number from the experimental Sherwood number, as shown in Eq. (6).

$$
\frac{N u_{\text {local }, A N S}}{S h_{\text {local }, \mathrm{Cur}}}=\left(\frac{R e_{\text {local,ANS }}}{R e_{C u r}}\right)^{0.8} \times\left(\frac{P r_{l o c a l, A N S}}{S c_{C u r}}\right)^{0.4}
$$

where:

$$
\begin{aligned}
& N u=\text { Nusselt number, } \\
& R e=\text { Reynolds number, } \\
& P r=\text { Prandtl number, } \\
& S h=\text { Sherwood number } \\
& S c=\text { Schmidt number. }
\end{aligned}
$$

Local wall temperatures were then estimated based on the extrapolated heat transfer coefficients. Unacceptably high wall temperatures were predicted approximately $30 \mathrm{~mm}$ into the channel for a $20-\mathrm{mm}$ edge blockage, corresponding to heat transfer coefficients from 500 to $50,000 \mathrm{~W} /\left(\mathrm{m}^{2} \cdot{ }^{\circ} \mathrm{C}\right)$. Heat transfer coefficients near the channel exit were estimated to be about $110,000 \mathrm{~W} /\left(\mathrm{m}^{2} \cdot{ }^{\circ} \mathrm{C}\right)$, and those near the inlet opposite the blockage were estimated at values up to $160,000 \mathrm{~W} /\left(\mathrm{m}^{2} \cdot{ }^{\circ} \mathrm{C}\right)$.

These extrapolations would indicate that an unheated entrance length of $10 \mathrm{~mm}$ should not be subjected to any entrance blockages larger than $6 \mathrm{~mm}$. The large degree of uncertainty associated with this estimate would indicate that a more conservative limit would be blockage sizes no greater than $3 \mathrm{~mm}$.

The estimate's uncertainty comes from several factors, including (1) the limited range of data, (2) the assumption of a constant mass flow through each channel, (3) the use of constant concentration (the mass transfer analogy for constant temperature) wall conditions to predict conditions for constant wall heat flux, (4) a threefold extrapolation in Reynolds number, (5) the mass transfer to heat transfer analogy, and (6) the use of a compressible fluid rather than an incompressible one. The Mach number for the Cur cases used was less than 0.2 , indicating that any compressibility effects would be very small. The first uncertainty reflects the use of only two blockage sizes, both placed in edge locations. The data gives no guidance regarding the relative behavior of blockages located away from the edge. Examination of central blockages for other, nonrectangular geometries, would indicate a better (shorter) recovery for blockages located away from the wall. The assumption of constant mass flow through each channel is reasonable only for small blockages. For larger blockages, the constant pressure inlet and outlet plenums connected by multiple parallel channels would result in greatly reduced flows in those channels with inlet blockages. Rough calculations show that the mass flow for a $50 \%$ blockage would be about $70 \%$ of the unblocked flow. This second factor is therefore highly nonconservative for large blockages. The third factor, that of using constant wall temperatures to predict effects for constant wall heat flux, would make almost no difference for a fluid with constant properties in a field with relatively small heat flux and uniform heat transfer properties. None of these conditions are valid for the ANS channel, where the viscosity shows a strong dependence on temperature, where the heat transfer coefficients vary widely between the region behind the blockage and the rest of the channel, and where the heat flux is large, causing a significant rise in the fluid temperature.

In summary, the differences between the available experimental data and the ANS configuration are significant. The extrapolations based on this experiment should be used only for rough guidance and provide no foundation for a design safety analysis. The original experimental data can however be used as an additional benchmark to improve the reliability of any computational fluid dynamics (CFD) model. 


\section{EXPERIMENTAL FACILITY DESCRIPTION}

Two experimental measurement techniques were chosen to measure the fluid behavior within the narrow channel. The first used thermochromic liquid crystals (TLC) to measure channel wall temperatures. The second used laser doppler velocimetry (LDV) to monitor the fluid flow within the channel. The experimental facility, shown in Fig. 3.1, was designed to accommodate both techniques and with the same channel dimensions as the proposed ANS fuel channel, $84 \mathrm{~mm}$ in span with a 1.27-mm gap and approximately $500 \mathrm{~mm}$ long (the channel span in the reactor varies depending on the fuel element of interest). Channel walls were machined flat Lexan surfaces. The channel gap was established by inserting a steel gasket with a thickness of $1.27 \mathrm{~mm}$ between the two Lexan plates. This gasket extended below the entrance plenum and above the exit plenum. A pump was installed to provide the full flow rate of $25 \mathrm{~m} / \mathrm{s}$ in an unblocked channel. Temperature and pressure sensors and flow meters were included to characterize the test conditions fully with accuracies of $\pm 1.2^{\circ} \mathrm{C},< \pm 1 \%$, and $\pm 1 \%$, respectively. The heat exchanger shown in this figure was used to maintain isothermal conditions by removing the small amount of energy added to the water by the pump.

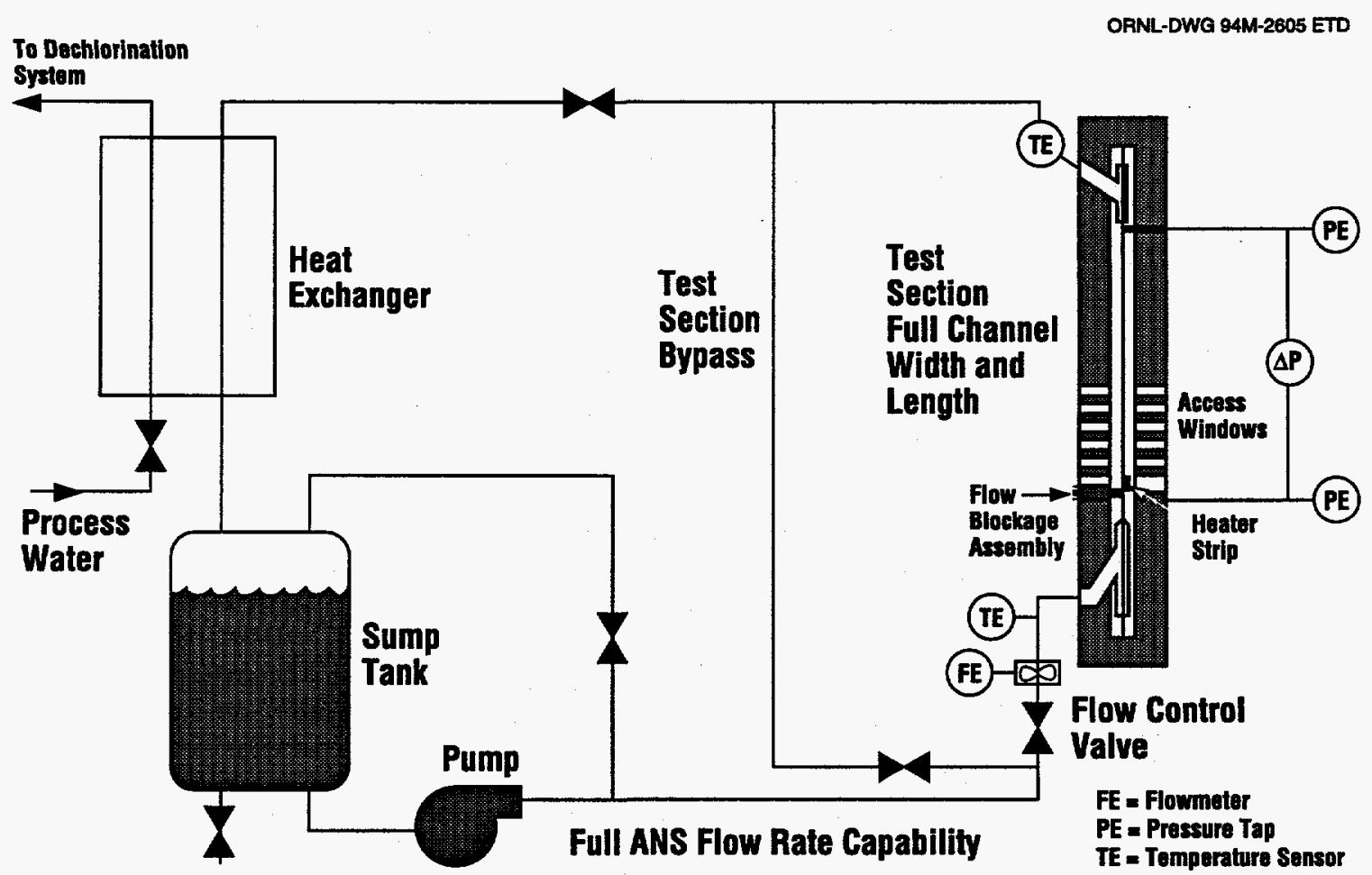

Fig. 3.1. Flow Blockage Test Facility schematic。

Water enters the center (spanwise) side of an inlet plenum, $180 \mathrm{~mm}$ long by $84 \mathrm{~mm}$ wide by $25 \mathrm{~mm}$ thick, at an angle of $30^{\circ}$. The top of the plenum narrows at a $45^{\circ}$ angle so that the gap is reduced from 25 to $2.54 \mathrm{~mm}$. The $2.54-\mathrm{mm}$ gap is maintained for $35 \mathrm{~mm}$. At this point the channel entrance is defined by an abrupt $\left(90^{\circ}\right)$ change in the channel gap to $1.27 \mathrm{~mm}$. Numerical models show that this flow conditioning produces uniform flow at the channel inlet in the absence of any blockage. The exit plenum is an abrupt expansion in the gap from 1.27 to $25 \mathrm{~mm}$. Because the channel length is equal to about 
200 hydraulic diameters $\left(d_{h}=2.5 \mathrm{~mm}\right)$, all observed flow phenomena were well recovered within the channel itself.

The flow blockage assembly was designed so that the blockage width and position could be easily changed, allowing a wide range of test conditions. The thickness of the blockage (in the direction of the flow) was $10 \mathrm{~mm}$. As shown in Fig. 3.2, the water flow is blocked by the tight fit between the metal blockage element and the Lexan side walls over both the $10-\mathrm{mm}$ depth of the blockage and the $0.635-\mathrm{mm}$ lip between the inlet region and the channel. This figure shows the side view of the channel entrance region, and the scale has been distorted to display both the blockage configuration and the heater plate installation in more detail. Because of differences between numerical model predictions and the experimental results for central blockages, the possibility of leakage around the blockage at the channel inlet was considered. One blockage assembly, a $35 \%$ central blockage, was modified to incorporate the gasket shown in Fig. 3.2 to ensure that no leakage could occur.

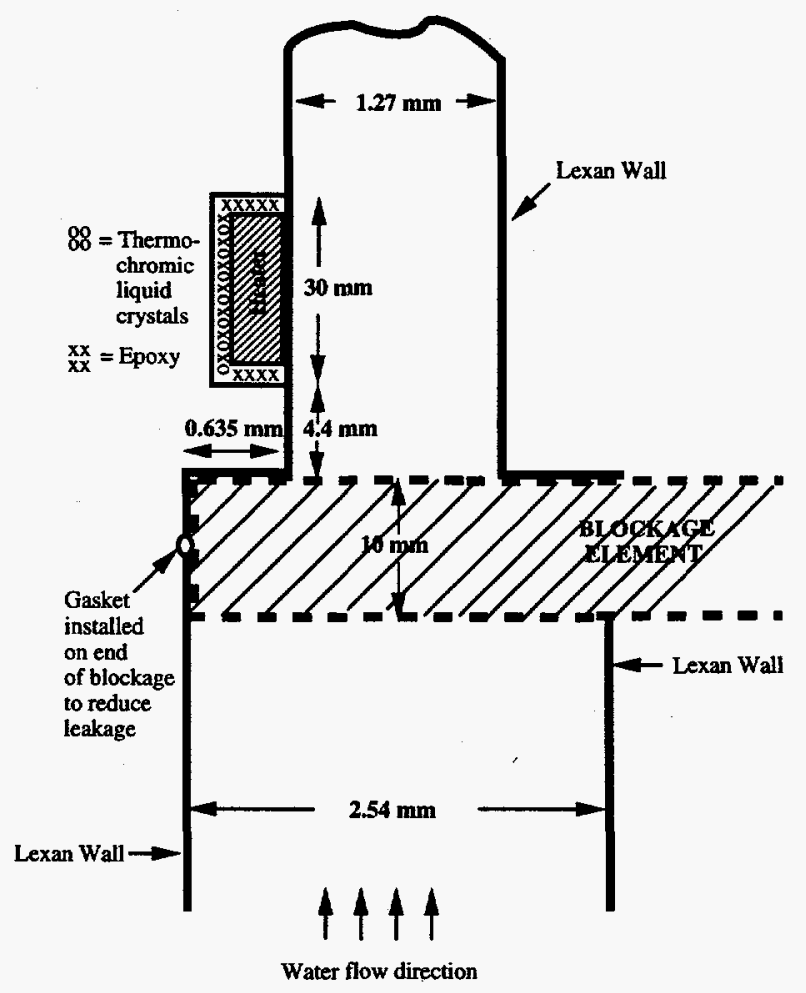

Fig. 3.2. FBTF channel side view. Not to scale.

\subsection{THERMOCHROMIC LIQUID CRYSTALS}

Thermochromic liquid crystals respond to temperatures by changing color and are available for a wide range of temperatures and a variety of resolutions. A portion of the wall near the blockage was devoted to a small heater to provide the uniform surface héat flux required for the TLC tests. The thin $(1-\mathrm{mm})$ stainless steel heater strip was imbedded in the wall of the channel as shown in Figs. 3.1 and 3.2. The heater started $4.4 \mathrm{~mm}$ from the downstream side of the blockage assembly and covered the entire 84-mm width of the channel and $30 \mathrm{~mm}$ of the channel's length. After removal from the test facility, the heater strip was immersed in water, and the electrical resistivity was measured $( \pm 3 \%)$ to be from 0.00219 to $0.00229 \Omega$ as the voltage was varied from 0.25 to $1 \mathrm{~V}$. A value of $0.0022 \Omega$ was used for all data 
analyses. The electrical current was measured for each test so that the heat flux from the heater surface could be calculated as shown in Eq. (7).

$$
q^{\prime \prime}=\frac{I^{2} \times R}{w \times L_{\text {heater }}},
$$

where:

$$
\begin{aligned}
& q^{\prime \prime}=\text { heat flux on heater surface, } \\
& I=\text { electrical current to heater, } \\
& R=\text { heater electrical resistance }(0.0022 \Omega), \\
& w=\text { heater width }(84 \mathrm{~mm}), \\
& L_{\text {heater }}=\text { heater length }(30 \mathrm{~mm}) .
\end{aligned}
$$

Thermochromic liquid crystals are rather fragile, and any direct exposure to channel flow would wash the crystals away from the heater surface. The crystals were therefore painted (over a thin base coat of black paint) on the back side of the heater plate, where they would not be in contact with the flowing water and would be visible through the clear Lexan. Although the heater fit tightly into the Lexan channel wall, it was difficult to maintain the proper flow channel dimensional tolerance on the heater surface. Indeed, the alignment of one portion of the heater face was off by approximately $0.08 \mathrm{~mm}$, resulting in a channel gap width variance of about $6 \%$ at that location, relative to the design gap width of $1.27 \mathrm{~mm}$. The heater power was adjusted for each test to produce heater wall temperatures within the measurable band, from 30 to $45^{\circ} \mathrm{C}$ for the selected crystals. Heater power was calculated based on the measured electrical current $( \pm 1 \%$ accuracy) and the heater resistance of $0.0022 \Omega$.

A color video camera and data conversion system were installed to record the temperature field. System components, calibration, and accuracy are described fully in an earlier paper. ${ }^{5}$ Early tests with the camera and various lighting arrangements used for the TLC tests showed that the recorded results were affected by slight changes in both direct and ambient lighting. A new algorithm for recording the color data was used to reduce this sensitivity, and the test lighting was held constant from the beginning of the calibration procedure until the end of the last test. An evaluation of system accuracy showed that the temperature measurements were accurate to within $0.2^{\circ} \mathrm{C}$. One lighting issue could not be eliminated. Because of the large pressure drop associated with high-speed fluid flow through the narrow channel, the Lexan channel walls were supported by a strong steel case approximately $50 \mathrm{~mm}$ thick. The access window for the video camera was cut through this steel case, giving a viewing area large enough to cover the heater surface of 30 by $84 \mathrm{~mm}$, but with very thick side walls. Both lights and the camera lens were directed into this window. Although a diffuse light source was used, some reflections from the 5-mmthick side wall of the access window were unavoidable. These reflections affect a small area very near the edge of the data collection region.

\subsection{LASER DOPPLER VELOCIMETRY}

The LDV technology uses intersecting laser beams and advanced optical data collection and processing equipment to measure the motion of individual minute particles as they pass through the created fringe pattern. Because the heater plate used for the TLC tests was not needed for the LDV experiments, a new Lexan side wall was fabricated. The side wall used for the LDV measurements was therefore smooth, without any of the heater-related anomalies that caused difficulties for the TLC system. 
The LDV system was manufactured by TSI, Inc. and was supplied with version 4.0 of their FIND analysis package. ${ }^{6}$ Two processors were used to provide two velocity components, axial and span. No velocity measurements were made in the gap direction. A beam retroreflector was used to increase the data collection rate.

The LDV system optical components were carefully chosen so that the measurement volume (i.e., the region where the laser beams intersect and moving particles are monitored) would fit within the confined gap of the FBTF channel. All the optical equipment was mounted on a three-dimensional traversing system able to position the measurement volume with an accuracy of $0.01 \mathrm{~mm}$ in each direction. The measurement volume diameter was $34 \mu \mathrm{m}$. The length of the measurement volume in the channel gap direction was $0.27 \mathrm{~mm}$, or about $1 / 5$ of the total channel gap. The measurement volume was positioned in the center of the channel's gap for all measurements. The center was located by adjusting the traversing system until the measurement volume included the channel wall, which was indicated by a sharp spike in zero-velocity measurements and by the decreased data collection rate. After the position of both bounding walls was identified in this manner, the traversing system was adjusted to place the measurement volume at the midpoint. Approximately 50 to 80 locations across the 84-mm channel span were monitored at each of the six observation windows. The number varied according to the observed flow phenomena, so that measurements were concentrated in areas of rapidly changing velocities. The large amount of turbulence found in a few of the tests was reflected by the wide range of velocity values monitored at a few localized points. To be sure that the full range was measured (i.e., that the signal processors were not clipping some of the data), the LDV signal processor was upgraded. Those tests showing the highest turbulence rates were then repeated, and the results compared with the data taken with the original processor. The velocity profiles and turbulent kinetic energy contours were unchanged. 


\section{NUMERICAL MODELS}

\subsection{BACKGROUND-MODELING THE SPARROW AND CUR EXPERIMENT}

Many CFD computer codes are available. ${ }^{7}$ Each code seeks to solve a complex system of equations, thereby describing fluid flow behavior on a highly localized basis for any number of geometrical configurations. These codes vary in their mathematical approach, using either a finite-difference or a finite- element approach, and offer a variety of solution techniques. Typically, these codes are leased, and significant training is required to produce useful analysis. The Fluent code was available to trained researchers at the Massachusetts Institute of Technology (MIT). Also, the Fluent code was based on a finite-difference methodology, preferred by the FBTF staff because of previous difficulties with a code based on a finite-element approach. ${ }^{8}$ Therefore, the MIT staff were asked to produce two numerical models. ${ }^{9}$

These initial models were designed with the simple goal of providing a more reliable extrapolation of the Sparrow and Cur data to ANS conditions. These efforts therefore focused on two physical simulations, one of Sparrow and Cur's experiment and the other on the ANS preliminary design. It was felt that, if the chosen CFD code could reproduce Sparrow and Cur's experimental results accurately, it could also accurately predict the fluid flow patterns within the ANS channel. These initial CFD results were disappointing. They accurately produced a qualitative picture of the recirculation region behind the blockage matching that of Sparrow and Cur. However, the size of this region was only about one-third of the recirculation region measured by Sparrow and Cur. This comparison showed not only that the numerical model was unable to match the experimental results, but that the errors were nonconservative. That is, they predicted better heat transfer than was experimentally measured. These results led to a comprehensive review of numerical modeling techniques and capabilities.

These first models of the Sparrow and Cur channel were developed using the Fluent computer code. The investigation that followed those initial disappointing results focused on (1) the computational grid definition, (2) inlet modeling, (3) turbulence modeling, (4) proper modeling of experimental hydrodynamics, (5) numerical modeling accuracy capabilities, (6) code selection, and (7) experimental error.

The computational grid, inlet model, and code selection were all examined by a comparative analysis using the FLOW-3D computer code. ${ }^{10}$ This code, in use at Oak Ridge National Laboratory for several years, is also a finite-difference code and offers three turbulence models, the most complex of which corresponds to the Fluent code's basic model. The FLOW-3D code uses a solution technique based on transient fluid flow phenomena that differs significantly from the steady-state solution technique employed by Fluent. Based on MIT's Fluent results, the grid size was improved by a factor of 5, and the flow inlet was modeled to represent the experimental conditions more realistically. The reattachment length predicted by $F L O W-3 D$ was double that predicted by the MIT effort. However, that length was still only two-thirds of the measured value and thus was unacceptable.

After the first comparative analysis indicated that the grid size, inlet model, and code selection could not account for all the differences between the model and the experiment, attention focused on the turbulence model. MIT used the standard $k-\epsilon$ model, expressing turbulence as a function of empirically derived constants for kinetic energy transport and dissipation. However, a study of available turbulence models showed that this model produces poor results for highly turbulent or separated flow, conditions that certainly occur in the region behind a partial flow blockage. The renormalized group (RNG) model developed by Princeton researchers and implemented within the Fluent code offers a better theoretical basis for turbulence predictions for such flow regimes. ${ }^{11}$ This study also revealed the necessity for experimental benchmarks for any CFD model. The numerical techniques used in any of the CFD codes 
are unable to provide an estimate of expected accuracy for the modeling results. Such confidence bounds can be supplied only by comparison to appropriate experimental results.

All the efforts described so far in this section deal with the CFD models. Another possibility was that of experimental error or inappropriate hydrodynamic modeling of the experimental conditions.

Discussions with both Sparrow and Cur, along with a detailed examination of the original experimental documentation, provided convincing arguments that the reported data were reliable. The effect of varying

naphthalene concentration in the air was considered, but discussions with Sparrow revealed that this value was never more than $10 \%$ that of the wall and was much less than that for the higher flow rate test cases used in these comparisons. Therefore, a constant mass concentration assumption for the air was appropriate.

Using Fluent and the RNG turbulence model improved the CFD model's prediction of the reattachment point but was still unacceptably nonconservative. A further improvement in the model was then made by extending the computational grid to almost 150,000 nodes and providing a model of the exit plenum as well as of the inlet plenum. This model was more successful, predicting a reattachment length that matched the experimental data within $10 \%$. This result produced a high degree of confidence in the RNG turbulence model, as well as in the capabilities of the Fluent CFD code.

\subsection{FLOW-3D MODELS FOR THE FLOW BLOCKAGE TEST FACILITY GEOMETRY}

As described, the FLOW-3D code was used to provide an independent comparison for the Fluent models. It was also used to explore grid and model issues. One such issue was the level of detail needed when modeling the inlet region for the FBTF. Figure 4.1 shows the geometry of this inlet region for a $50 \%$ edge blockage. The water enters the plenum at an angle of $30^{\circ}$. The plenum narrows to a thickness of $2.54 \mathrm{~mm}$. At the downstream face of the blockage, there is a square-edged reduction to a thickness of $1.27 \mathrm{~mm}$. Three modeling options were reviewed and tested by comparing the resulting velocity profiles at the blockage. The first option is shown in Fig. 4.1 and represents a full model of the inlet region. The results of this model were used as the basis for judging the adequacy of the other, simpler models. The second option included the inlet plenum but not the angled inlet pipe. Instead, the water was introduced at the appropriate $30^{\circ}$ angle directly into the rectangular plenum area. The third option was simpler yet and amounted to specifying a uniform velocity in the channel opening beside the blockage (this third option matches the approach used in the original MIT model). The second option produced a velocity profile at the blockage almost identical to that produced by the more complex model shown in Fig. 4.1. This velocity profile is shown in Fig. 4.2 , where the inlet blockage extends from $y / w=0$ to 0.5 . This nonuniform velocity profile demonstrates the importance of including some portion of the inlet plenum in all future models.

Further efforts to use the $F L O W-3 D$ code to model the FBTF were less successful. Based on our requests and the code's inability to approximate the empirical data, Flow Science personnel added the RNG turbulence model to FLOW-3D. However, differences between the model predictions and experimental results persisted. The extent of these differences is best shown by the difference in the overall mass flow rate through the channel for a specified pressure drop. $F L O W-3 D$ underpredicted the mass flow by 10 to $12 \%$. Given this low flow rate, it is not surprising that the wall heat transfer coefficients (both locally and averaged over the wall region) were also underestimated by more than $50 \%$. These inaccuracies persisted even when grids up to eight times finer (in the direction normal to the walls) than those used for the Fluent models were specified. Also, the code's transient solution technique was poorly suited to the FBTF steady-state problem, leading to computational times measured in weeks. 


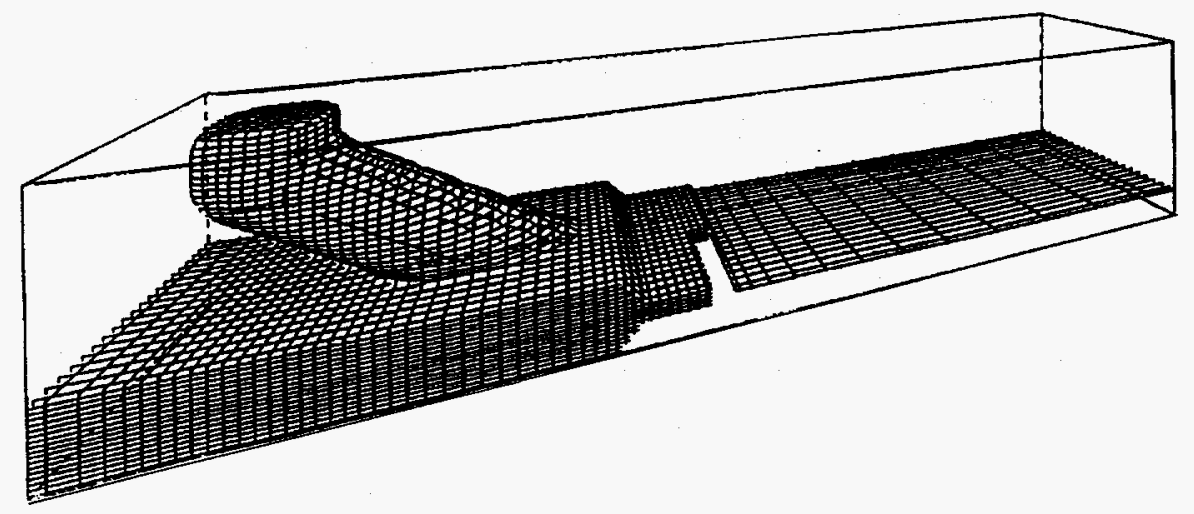

Fig. 4.1. Full CFD model of inlet region.

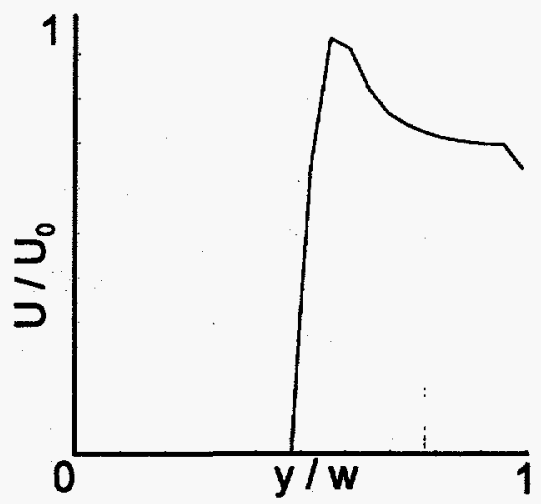

Fig. 4.2. Inlet velocity profile.

\subsection{FLUENT MODEL DESCRIPTIONS}

For any analysis based on CFD, important issues must be addressed, including (1) proper modeling of the physical hydrodynamics, including inlet and outlet regions and all boundary conditions, (2) the computational grid definition, (3) the proper selection of a turbulence model, and (4) other possible code errors. Whenever experimental and numerical analysis results are compared, experimental error must also be considered.

Most of the CFD models developed during this analysis reflect the FBTF geometry. These models are primarily used to benchmark the code for the ANS channel geometry. Since the FBTF itself was designed to match ANS fuel channel geometry, this approach should provide a sound basis for the safety analysis. The pressure sensors on the FBTF, shown on Fig. 3.1, are located in the entrance plenum and within the cooling channel, $469 \mathrm{~mm}$ from the channel inlet. The length of the channel in the CFD model was therefore set equal to $469 \mathrm{~mm}$, giving a length-to-gap ratio of 370 . The span was set equal to the FBTF 
span, $84 \mathrm{~mm}$, giving a span-to-gap ratio of 66 . The channel hydraulic diameter is $2.50 \mathrm{~mm}$, so the model's $\mathrm{L} / \mathrm{d}_{\mathrm{b}}$ ratio was 188 , and the $\mathrm{S} / \mathrm{d}_{\mathrm{b}}$ ratio was 35 . Because the downstream pressure measurement was made within the channel, the outlet boundary condition was defined by the pressure at this location, and the exit plenum was not modeled. The inlet boundary condition was specified by the pressure and temperature of the fluid at the plenum inlet. The channel side walls $(1.27 \times 469 \mathrm{~mm})$ were considered adiabatic for all analyses. Boundary conditions for the wall representing the fuel plate $(84 \mathrm{~mm}$ wide) varied among the models. For some cases, the small local heat flux provided by the heater plate in the TLC tests was modeled. For other cases, the wall was considered to be adiabatic, which is appropriate for the plain Lexan walls used in the LDV tests. Finally, for a few cases run after the benchmarking efforts were complete, one representative heat flux pattern from the ANS design data was mapped onto the wall. All fluid properties for the cases compared with experimental data were those of water at room temperature. This method was appropriate because the water temperature never rose more than 1 to $2^{\circ} \mathrm{C}$ within the channel.

For those cases designed to mimic ANS conditions with higher wall heat fluxes, temperaturedependent properties for liquid $\mathrm{D}_{2} \mathrm{O}$ were used. Every blockage considered was assumed to cover the entire width of the gap $(1.27 \mathrm{~mm})$ and at least three adjacent fuel channels. This conservative assumption provides symmetric boundary conditions along the center plane of the channel, as shown by symmetry plane A in Fig. 4.3. An additional plane of symmetry, parallel to plane A and located $0.635 \mathrm{~mm}$ away from the channel's wall surface, passes through the center of the fuel plate. Another plane of symmetry for unblocked or central blockage models is located at the center of the channel's span, as shown by plane $\mathrm{B}$ in Fig. 4.3. Recognizing these symmetrical physical conditions permits a more efficient computational model. As a result of the studies examining the inlet plenum region, and presented in Sect. 4.2, a region $50 \mathrm{~mm}$ long was used to model the inlet plenum upstream of the fuel channel. The plane of symmetry through the fuel plate extends out into the entrance plenum region. This symmetry within the plenum region is an accurate representation of the ANS geometry. However, the FBTF geometry is limited to one flow channel, so the bounding conditions in the plenum are side walls (because the FBTF plenum gap thickness is twice the channel gap thickness). The pressure drop resulting from wall friction in the plenum region is negligible compared to the pressure drop at the channel entrance and that resulting from wall friction within the channel. Nevertheless, one blockage model included the plenum wall boundary to test the sensitivity of the results to this factor.

The grid dimensions for the Fluent CFD models are primarily determined by the small gap dimension. Because wall functions are used with Fluent's RNG turbulence model, the cell nearest the wall must be large enough to extend beyond the boundary layer. Fluid velocities in the recirculation region behind a blockage are much lower than those in the rest of the channel. The code accounts for this variability by iteratively calculating the nondimensional distance, $\mathrm{y}^{+}$, for each cell near a wall. If this value indicates that the border of the computational cell is within the boundary layer, laminar correlations are used to calculate the local velocity vectors. When five equal elements were used across the half-gap distance of $0.635 \mathrm{~mm}$, the turbulent wall functions were appropriate for most of the channel. Laminar conditions typically occurred in only a few cells at the center of the recirculation region and near the reattachment point. Grid densities in the remaining two directions were chosen to provide reasonable aspect ratios for the cells near the channel entrance. Because the channel is so much longer than it is thick, the cell aspect ratio was allowed to grow farther away from the entrance to reduce computational requirements. Preliminary two-dimensional models were used to investigate the impact of grid variations in the axial and gap directions and the adequacy of the 50-mm inlet region before the fuel plate. These models showed that 5 cells in the gap direction and 150 cells in the axial direction produced the expected mass flow rate for the specified pressure drop and converged well. Eight cells were used across the $1.27-\mathrm{mm}$ gap in the inlet region. For unblocked and center blockage cases, 28 cells were used across the half-span of $42 \mathrm{~mm}$. This grid performed well in matching the expected mass flow and heat transfer coefficients on the channel walls for the unblocked case. The spanwise cell divisions were spaced to 


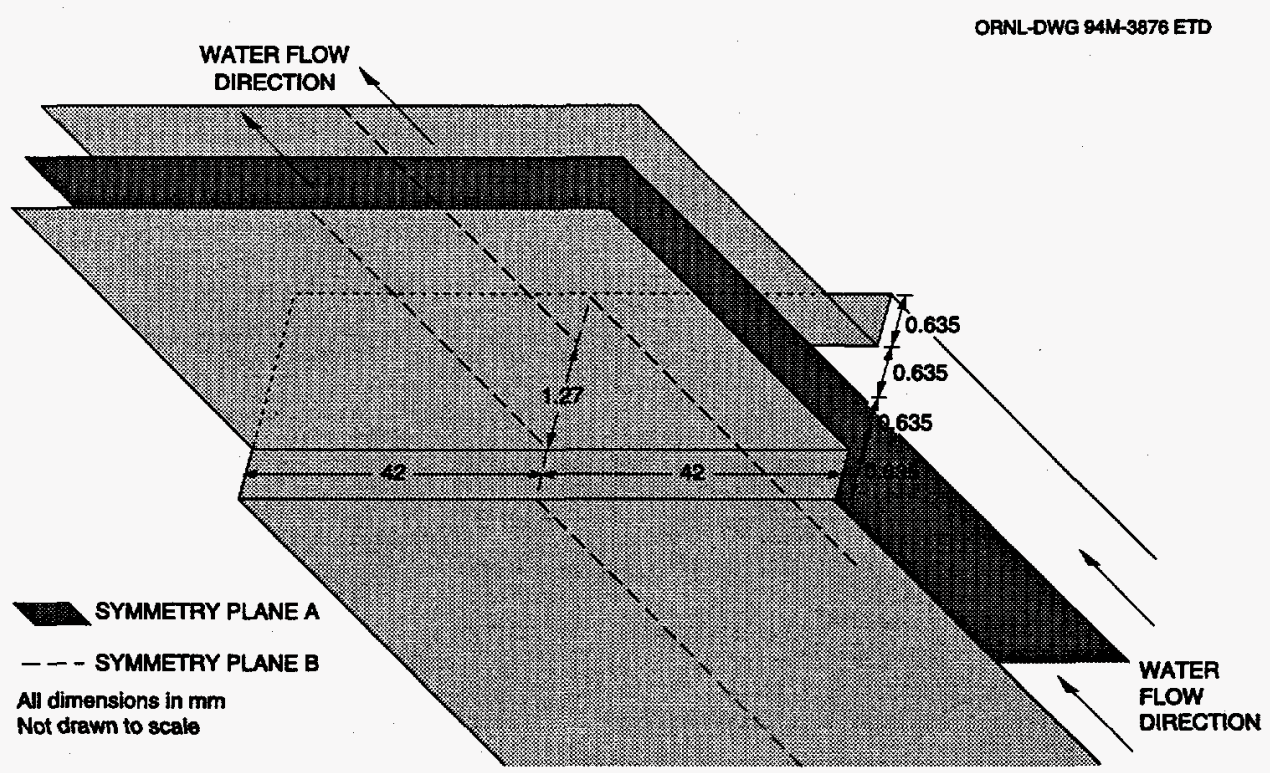

Fig. 4.3. Numerical model geometry at the channel inlet.

provide smaller cells near the side walls and near the blockage. For edge blockages, 56 cells were used across the full span width of $84 \mathrm{~mm}$. The spanwise grid arrangement was doubled for several cases to investigate the grid's adequacy. An idealized thin blockage was used for many preliminary analyses, but a more accurate inlet plenum with a finer axial grid mesh and a 10-mm-thick blockage was also modeled to assess the adequacy of this simplified model. Results from the improved plenum model matched the empirical data better than the simplified model. All results presented in the report are based on this improved plenum model.

The RNG turbulence model developed by Princeton researchers and implemented within the Fluent code was used for most of the CFD models. Like the standard k- $\epsilon$ model, the RNG model is a twoequation simplification and assumes isotropic stress fields. A Reynolds Stress Model (RSM) is much more computationally intensive but allows the calculation to consider nonisotropic turbulent stresses. The RSM model was used for a few selected cases to evaluate the acceptability of the RNG model and for direct comparison to experimental results, as is discussed later in this report. Within the Fluent code, turbulence conditions at an inlet are defined by the turbulence intensity, the ratio of the turbulent fluctuations in velocity to the mean flow velocity, and a characteristic length, representative of the model's geometry. The turbulence intensity is used to calculate the turbulent kinetic energy, which is in turn used with the characteristic length to calculate the turbulent energy dissipation rate. For most of the numerical models constructed, the turbulence intensity at the inlet plenum was set at $10 \%$, and the characteristic length was set equal to the channel gap, $1.27 \mathrm{~mm}$. For a few cases, the turbulence intensity was set at $2 \%$ to investigate the sensitivity of the results to this parameter. Comparing these cases, the point of flow reattachment was unchanged. Also, the turbulent kinetic energy peak value and overall distribution within the channel were unchanged. Apparently, the turbulence generated as the flow enters the channel and flows around the blockage element dwarfed any effect of the assumed turbulence at the plenum entrance. 


\section{EXPERIMENTAL DATA ANALYSIS}

\subsection{THERMOCHROMIC LIQUID CRYSTAL EXPERIMENTS}

If the fluid temperature within the channel is constant and there is a constant heat flux over the surface of the channel wall, then the wall temperature field will reflect the variations in the convective heat transfer coefficient over the wall surface. For small heat flux values and large fluid flow rates, this assumption of constant fluid temperature is a good approximation. For the maximum experimental heat flux and the design flow rate, the bulk fluid temperature rise would be only $0.03^{\circ} \mathrm{C}$. For a localized area in the center of a recirculation pattern behind a flow blockage, the fluid temperature could become elevated to some level greater than the overall bulk temperature. Then the measured temperature will reflect the combined effect of elevated fluid temperature and reduced fluid velocity. For these small areas, the assumption of constant fluid temperature used to evaluate the experimental data will produce a heat transfer coefficient less than the actual local value. This error will therefore be conservative and will also be reduced by high levels of turbulence.

A constant wall heat flux can be closely approximated using electrical resistance heating within the wall material. The electrical resistivity of stainless steel is a function of temperature, and the heat flux is proportional to the resistivity. The assumption of uniform internal heat generation, and therefore a constant heat flux over the heater surface, was carefully evaluated. For the temperatures experienced within the heater strip, the electrical resistivity will vary less than $2 \%$, and a detailed electrical analysis showed that the internal heat generation will vary less than $3 \%$. The heat flux was therefore assumed constant for all data analyses.

Sophisticated programing was developed to enhance the data collection and analysis. The code is titled FBTF Image and was based on the public domain software NIH Image, developed by the National Institute of Health. ${ }^{5}$ It was modified (1) to decrease the lag time between the red, green, and blue scans, (2) to provide flexibility over the red-green-blue (RGB) to 8-bit color conversion, and (3) to automate the entire calibration, data conversion, and image acquisition process. All images are digitally tagged with their respective test parameters as well as other useful information including blockage size and location. This program not only allows for in-depth posttest analysis, but is also an integral part of the test procedure itself, performing calibration tasks and providing real-time feedback for all test conditions. This monitoring aspect was used by the test operator as guidance in adjusting the power feed to the heater.

The algorithm chosen to interpret the heater's color pattern was the subject of intense scrutiny. The method originally proposed was unacceptably sensitive to small changes in lighting conditions. This original method relied on the construction of a color lookup table (LUT) from the colors recorded at various temperatures during an unblocked case. Each color was defined from its relative contributions of red, green, and blue. A 256-color LUT was then obtained by interpolating between the recorded calibration colors. However, this method relied heavily on consistent lighting conditions. It was at this point that a different color model that was relatively insensitive to variations in lighting was adopted for all FBTF analyses. This color model described color in hue, saturation, and value (HSV) rather than RGB. Figure 5.1 shows that the HSV method was far less sensitive to changes in lighting than was the original RGB method.

Because the crystals were located on the back of the thin heater strip, i.e., the side of the heater strip away from the channel flow, the recorded colors reflect the wall temperature after heat conduction through the heater strip and the paint. Any heat conduction through the thick Lexan window on the Lexan side of the plate will be negligible compared to the convective heat transfer on the channel side of the plate. Also, temperature change across the thin coat of paint was assumed to be negligible. The 


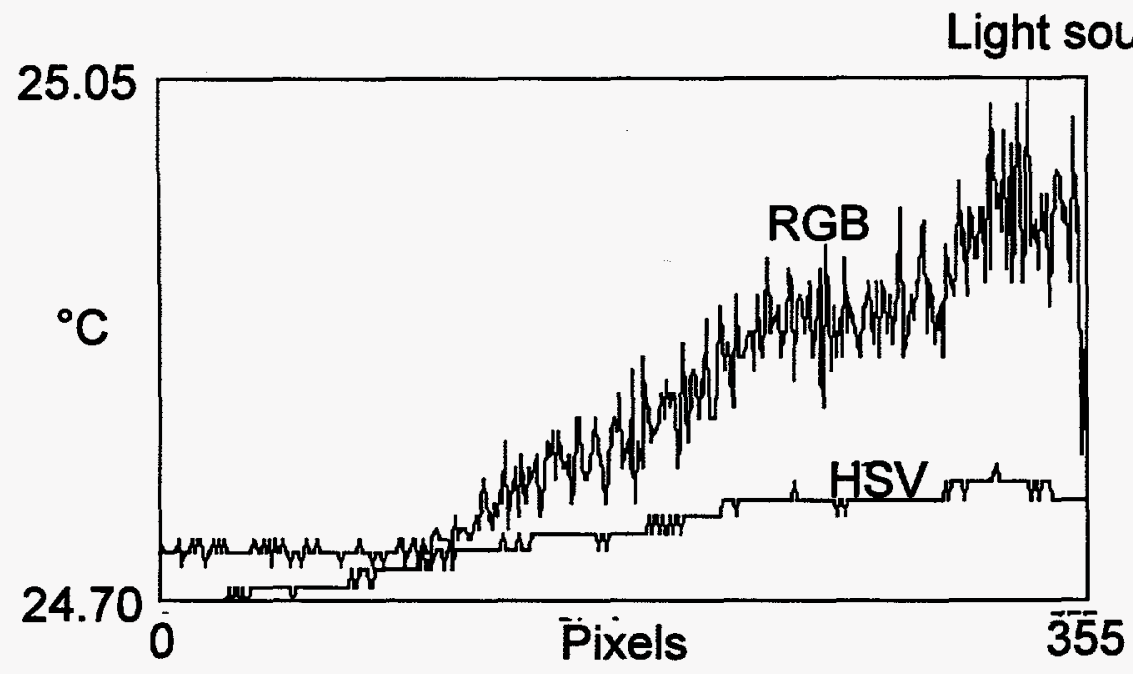

Fig. 5.1. Comparison of light sensitivity for HSV and RGB.

dimensions of the heater strip $(1 \times 30 \times 84 \mathrm{~mm})$, the low total heat generation $(<300 \mathrm{~W})$, and the resulting small temperature gradients (measured temperature differences usually $<3^{\circ} \mathrm{C}$ ) ensured that any conduction along the width or length of the heater strip would be considerably less than that through the much smaller thickness. This assumption of one-dimensional heat transfer with a material conductivity of $14 \mathrm{~W} /\left(\mathrm{m} \cdot{ }^{\circ} \mathrm{C}\right)$ was used for all data analyses. The only locations at which this assumption might cause measurable errors are near the edges of the heater, where thick electrical assemblies can act as heat sinks. However, lighting difficulties near these edges make the color data less accurate in these regions, negating any advantage that could be gained from a more rigorous treatment of the internal heat conduction in this region.

Based on the assumptions of constant bulk fluid temperature, uniform internal heat generation, uniform heat flux, negligible heat transfer through the Lexan window (i.e., the outside surface of the heater plate is adiabatic), and one-dimensional heat transfer through the heater, the wall temperature and heat transfer coefficient are evaluated as shown in Eqs. (8) and (9).

$$
\begin{gathered}
T_{\text {wall }}=T_{\text {crystal }}-\frac{q^{\prime \prime} \times t}{2.0 \times k_{\text {heater }}}, \\
h=\frac{q^{\prime \prime}}{T_{\text {wall }}-T_{\text {bulk }}},
\end{gathered}
$$

where

$T_{\text {wall }}=$ wall temperature,

$T_{\text {cnstal }}=$ temperature recorded by TLC field, $q^{\prime \prime}=$ heat flux, 
$t=$ thickness of heater plate $(1 \mathrm{~mm})$,

$k_{\text {heater }}=$ heater conductivity,

$h=$ convective heat transfer coefficient,

$T_{\text {bulk }}=$ fluid bulk temperature.

\subsection{LASER DOPPLER VELOCIMETRY EXPERIMENTS}

Sophisticated statistical methods are employed to evaluate the large amounts of data, about 1000 data points, produced by the LDV system for each observation point. Figure 5.2 shows a typical data distribution for one velocity component at one such point. The FIND analysis software evaluates these data values to calculate the mean, standard deviation, skewness, flatness, and turbulence intensity for the velocity in each of the two measured directions. The raw data values are also saved and used separately to calculate the turbulent kinetic energy. Both the LDV data analysis and the Fluent CFD code are based on the turbulent velocity model shown in Eq. (10).

$$
u_{i}=\bar{u}_{i}+u_{i}^{\prime},
$$

where

$u_{i}=$ velocity vector at a point,

$\bar{u}_{i}=$ time-averaged velocity,

$u_{i}^{\prime}=$ fluctuating velocity component (velocity perturbation).

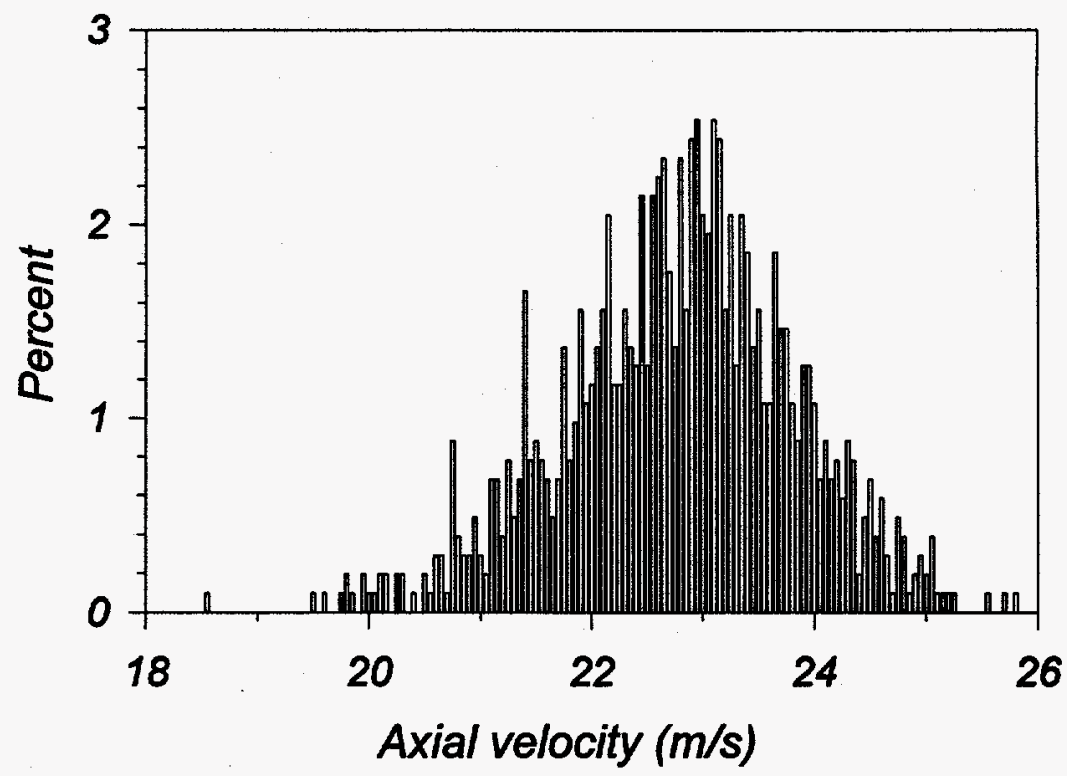

Fig. 5.2. Typical data distribution for LDV system. 
The turbulent kinetic energy is defined from the LDV data by calculating the absolute value of the flow perturbation from the mean for each data point and calculating the average perturbation. The average of the absolute value of the velocity perturbation for each velocity component is then used as shown in Eq. (11) to determine the turbulent kinetic energy for each velocity component.

$$
k_{i}=\frac{1}{2} \overline{u_{i}^{\prime 2}},
$$

where

$k_{i}=$ turbulent kinetic energy in the $i$ direction and

$u_{i}^{\prime}=$ absolute value of the turbulent flow perturbation in the $i$ direction.

Flow rates and kinetic energy terms were normalized relative to the average fluid velocity at the channel exit, i.e., the volumetric flow rate divided by the channel's cross-sectional area of $107 \mathrm{~mm}^{2}$. 


\section{EXPERIMENTAL RESULTS}

An unblocked experiment was made to compare the conditions within the FBTF to the design parameters of the ANS fuel channel. A pressure drop of 1.44 MPa produced the design flow rate of $25 \mathrm{~m} / \mathrm{s}$ through the unblocked channel. This value corresponds well to the design value of $1.4 \mathrm{MPa}$ for the preliminary ANS design. Tests were then made for a variety of blockage sizes, in both center and edge locations. These tests include cases with an unblocked channel, edge blockages of 10 and $25 \%$, and central blockages of 35 and $40 \%$. Tests were made for Reynolds numbers (based on average axial velocity at the channel exit) varying from 16,000 to 86,000 .

During the initial TLC tests, it became apparent that the heater surface was not perfectly aligned with the rest of the channel wall, although it was much improved over previous heater configurations. As expected, the heat transfer coefficients calculated from the measured wall temperatures for an unblocked test were depressed near the side walls. However, a small region of highly elevated heat transfer (or reduced wall temperature) was found very near the lip of the heater plate on the left side of the span. This region was caused by a slight elevation, relative to the Lexan wall surface, of the heater surface on the opposite side of the channel. This small bump caused a redistribution of the cooling water flow, which in turn caused a region of enhanced heat transfer in all the test data. In most tests, the wall temperature in this area was indistinguishable from the bulk fluid temperature. For the unblocked case, the average convective heat transfer coefficient for the latter $2 / 3$ of the heater plate (axial locations from 15 to $35 \mathrm{~mm}$, or 6 to $\left.14 \mathrm{~d}_{\mathrm{h}}\right)$ was $105 \mathrm{~kW} /\left(\mathrm{m}^{2} \cdot{ }^{\circ} \mathrm{C}\right.$ ) [with a standard deviation of $15 \mathrm{~kW} /\left(\mathrm{m}^{2} \cdot{ }^{\circ} \mathrm{C}\right)$ ]. For comparison, Nusselt's correlation for convective heat transfer in the entrance region of a smooth tube, shown in Eq. (12), with properties for water at room temperature, the design velocity of $25 \mathrm{~m} / \mathrm{s}$, and at an axial location of $8 \mathrm{~d}_{\mathrm{h}}$, produces a heat transfer coefficient of $116 \mathrm{~kW} /\left(\mathrm{m}^{2} \cdot{ }^{\circ} \mathrm{C}\right){ }^{3}$

$$
N u=0.036 \times(R e)^{0.8}(P r)^{1 / 3}\left(x / d_{h}\right)^{-0.055},
$$

where

$\mathrm{Nu}=$ Nusselt number,

$R e=$ Reynolds number,

$P r=$ Prandtl number,

$x=$ axial position,

$d_{h}=$ hydraulic diameter.

The actual bulk fluid conditions within the ANS vary throughout the channel because of the variation in heat flux and the temperature-dependent properties of $\mathrm{D}_{2} \mathrm{O}$.

Each TLC test showed a distinct region of reduced heat transfer behind the blockage. The region of reduced heat transfer has a relatively constant width over the first $34 \mathrm{~mm}$ of the channel's length and is approximately equal to the width of the blockage itself for almost every central and edge blockage size tested. The one exception was the $10 \%$ edge blockage where the experimental data show an affected region about twice as wide as the blockage itself. These results are questionable because of the light reflections near the channel edge discussed previously.

The temperature difference across the heater plate ranged from 1 to $3^{\circ} \mathrm{C}$ for most of the test results. When using these results, the accuracy of the crystals $\left(0.1\right.$ to $\left.0.2^{\circ} \mathrm{C}\right)$ must be kept in mind. Also, the $6 \%$ distortion of the channel gap has an effect on the results. With these caveats, there is still some useful qualitative information available from the TLC test data. For the $25 \%$ edge blockage at a Reynolds number of 79,000, shown in Fig. 6.1, the temperature difference is about $4^{\circ} \mathrm{C}$, which indicates that the 


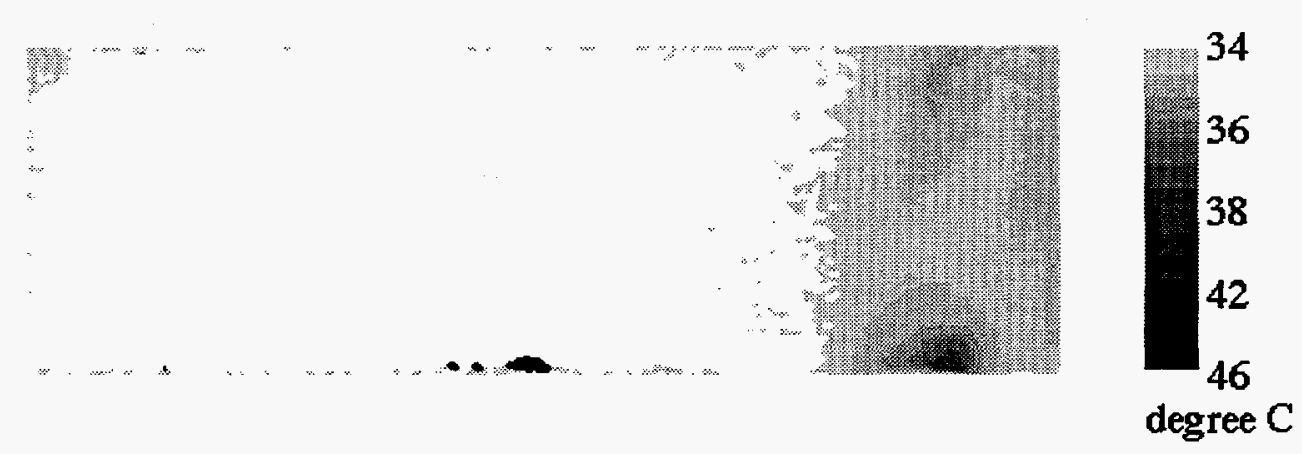

Fig. 6.1. TLC field temperature with $25 \%$ edge blockage at $\operatorname{Re}=\mathbf{7 9 , 0 0 0}$.

minimum heat transfer coefficient behind the blockage is about $1 / 4$ that in the unblocked channel. For central blockages at similar Reynolds numbers, the penalty is not so great, and the minimum heat transfer coefficients are at least $50 \%$ that of the unblocked channel. This trend continues for the lower Reynolds number tests, with the ratio of minimum to maximum heat transfer on the heater surface about $1 / 3$ for the $25 \%$ edge blockage and about 50 to $75 \%$ for central blockages ranging from 15 to $35 \%$ in size.

Tests with a $35 \%$ center blockage were made with and without the blockage gasket described previously for Reynolds numbers of 49,000 and 75,000. After the gasket was installed, the heat transfer measured behind the blockage decreased, and that measured in the free-stream regions on both sides of the blockage increased. The difference was slightly greater for the lower Reynolds number of 35,000, where the minimum heat transfer coefficient at the axial position $30 \mathrm{~mm}$ from the blockage $\left(12 \mathrm{~d}_{\mathrm{h}}\right)$ declined from 56 to $20 \mathrm{~kW} /\left(\mathrm{m}^{2} \cdot{ }^{\circ} \mathrm{C}\right)$. For the $\mathrm{Re}=75,000$ case, the minimum heat transfer coefficient at the same axial location decreased from 70 to $40 \mathrm{~kW} /\left(\mathrm{m}^{2} \cdot{ }^{\circ} \mathrm{C}\right)$. As can be seen Fig. 6.2 , the temperature difference is on the order of 1 to $2^{\circ} \mathrm{C}$ rather than 3 to $4^{\circ} \mathrm{C}$ for the edge blockage. (Comparing the edges of this figure to Fig. 6.1 shows how the crystals were gradually washed away from the edges of the heater, despite their epoxy casing, over the course of the testing program). These results indicated the gasket was probably eliminating or reducing some water leakage, so the gasket was left in place for all subsequent $35 \%$ center blockage tests.
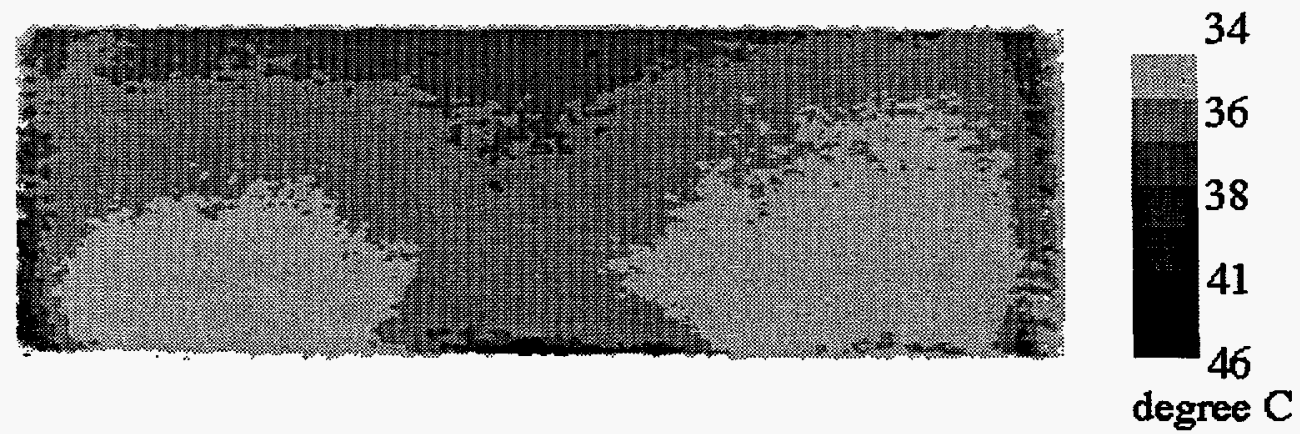

Fig. 6.2. TLC field temperature with $35 \%$ center blockage at $\operatorname{Re}=75,000$.

The availability of LDV data for both edge and central blockage cases allows a more detailed look at the flow phenomena. Figures 6.3 and 6.4 show the axial and spanwise velocities measured by the LDV for a $25 \%$ edge blockage (located from $y / w=0$ to 0.25 ) at a Reynolds number of 85,000 . When the tests 


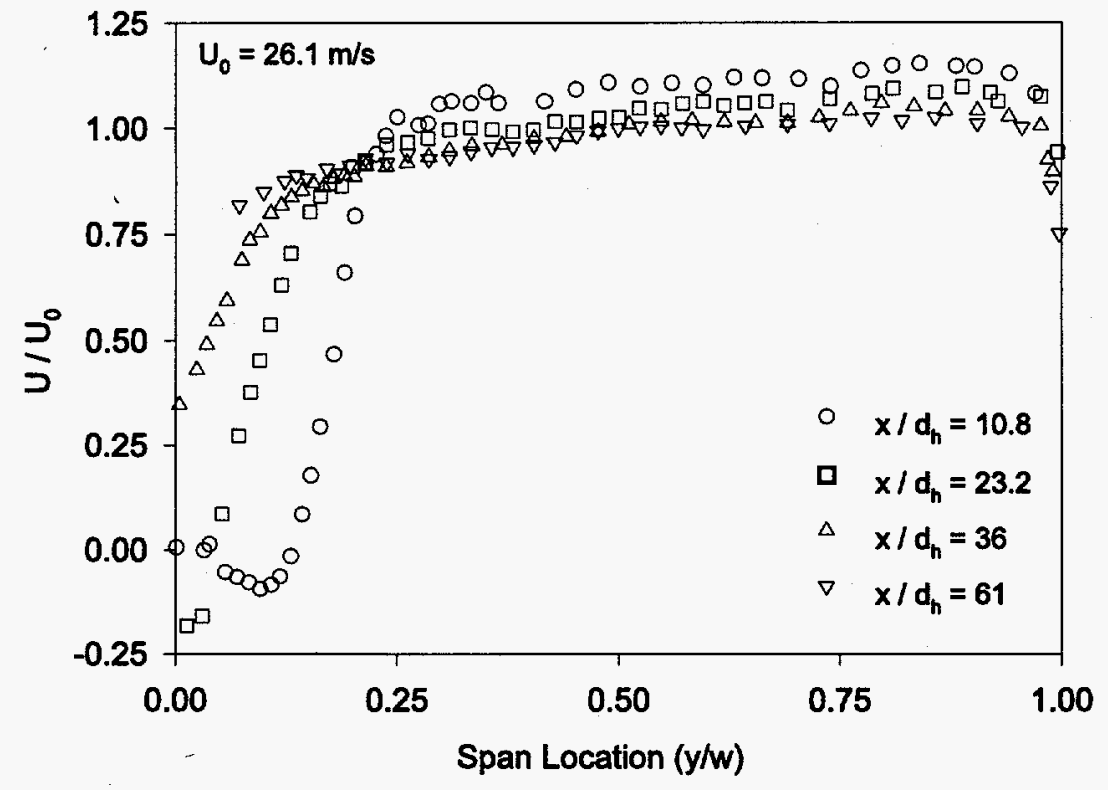

Fig. 6.3. Axial velocity profiles with $25 \%$ edge blockage at $\operatorname{Re}=85,000$.

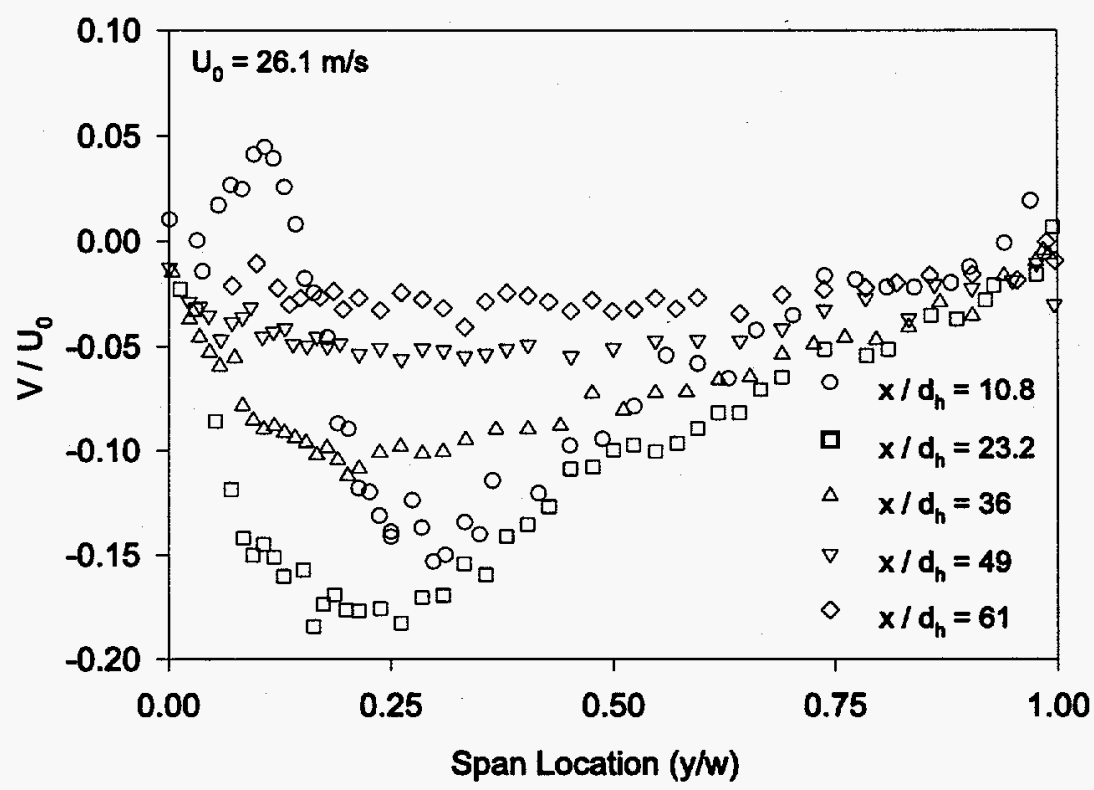

Fig. 6.4. Spanwise velocity profiles with $25 \%$ edge blockage at $\operatorname{Re}=85,000$. 
were repeated under similar conditions, $\operatorname{Re}=78,000$, the results were almost identical. The LDV data bracket the reattachment (transition to fully forward flow) between windows 2 and 3 indicating an axial position between 50 and $90 \mathrm{~mm}$ down the channel. This range corresponds to 20 to $36 \mathrm{~d}_{\mathrm{h}}$, or 2.4 to 4.3 times the blockage width. Sparrow and Cur found that reattachment for a $25 \%$ edge blockage occurred at 6.6 times the blockage width for a $\operatorname{Re}$ of 35,000 . $^{1}$ The kinetic energy terms from the LDV data for the $25 \%$ edge case (where again the blockage is located from $y / w=0$ to $y / w=0.25$ ) range from 0.2 to 4.6 $\mathrm{m}^{2} / \mathrm{s}^{2}$, with the axial component about twice the spanwise kinetic energy, as shown in Figs. 6.5-6.7.

The initial LDV experiments with the $35 \%$ central blockage showed unexpected behavior: the flow was fully forward in the first measurement window, less than one blockage width downstream from the blockage. The blockage element included the gasket that was discussed previously, but the possibility of leakage was revisited because of the unexpected short length of the flow recovery. The blockage assembly is held in place by two bolts, and the pressure that the blockage places on the opposite channel wall, made of Lexan, is controlled by the tightness of two nuts. When the position of these two nuts was varied, the expected flow recirculation appeared in the first observation window. Apparently, a blockage located in the center of the channel is able to distort the Lexan, permitting leakage around the blockage and possibly also causing further channel distortion in the areas beside the blockage. This distortion was further evidenced by asymmetry in both the spanwise velocity and the kinetic energy terms in the data from these initial experiments. The final blockage position (in the gap dimension) was chosen because it produced the greatest velocity defect and because the results show the expected symmetry. These two factors indicate that this position accurately creates the desired central blockage geometry.

Figures 6.8 and 6.9 show the normalized axial and spanwise velocity profiles for $35 \%$ center blockage tests at Reynolds numbers of 35,000 and 81,000 . Here the inlet blockage was located from $y / w=0.325$ to 0.675 . The results show very little change across this range of fluid velocities. For both cases, the flow was negative in the center of the first observation window but fully forward before the second, showing that the flow recovery occurs further upstream than for a smaller (25\%) blockage in the edge position. The nearly uniform velocity profile at $\mathrm{x} / \mathrm{d}_{\mathrm{h}}=40$ shows that the flow disturbance will be fully recovered long before the channel exit at $x / d_{h}$ of 200 . The water flowing from the edge regions toward the center of the channel produces the symmetric velocity profiles in Fig. 6.9, where the spanwise velocity is counted positive as it flows from left to right.

The turbulent kinetic energy for the $35 \%$ center blockage, located from $y / w=0.325$ to 0.675 , is shown in Fig. 6.10. There is little change in the turbulent kinetic energy distribution from the first to the second observation window (i.e., from 11 to $23 d_{h}$ ). The spanwise component peaks near the center of the channel at about $22 \mathrm{~m}^{2} / \mathrm{s}^{2}$. The axial component peaks at the edges of the recirculation region, directly behind the edges of the blockage, at about the same value. In the free-flow regions of the channel away from the blockage, the axial turbulent kinetic energy is greater than the spanwise, although they are both less than $3 \mathrm{~m}^{2} / \mathrm{s}^{2}$. 


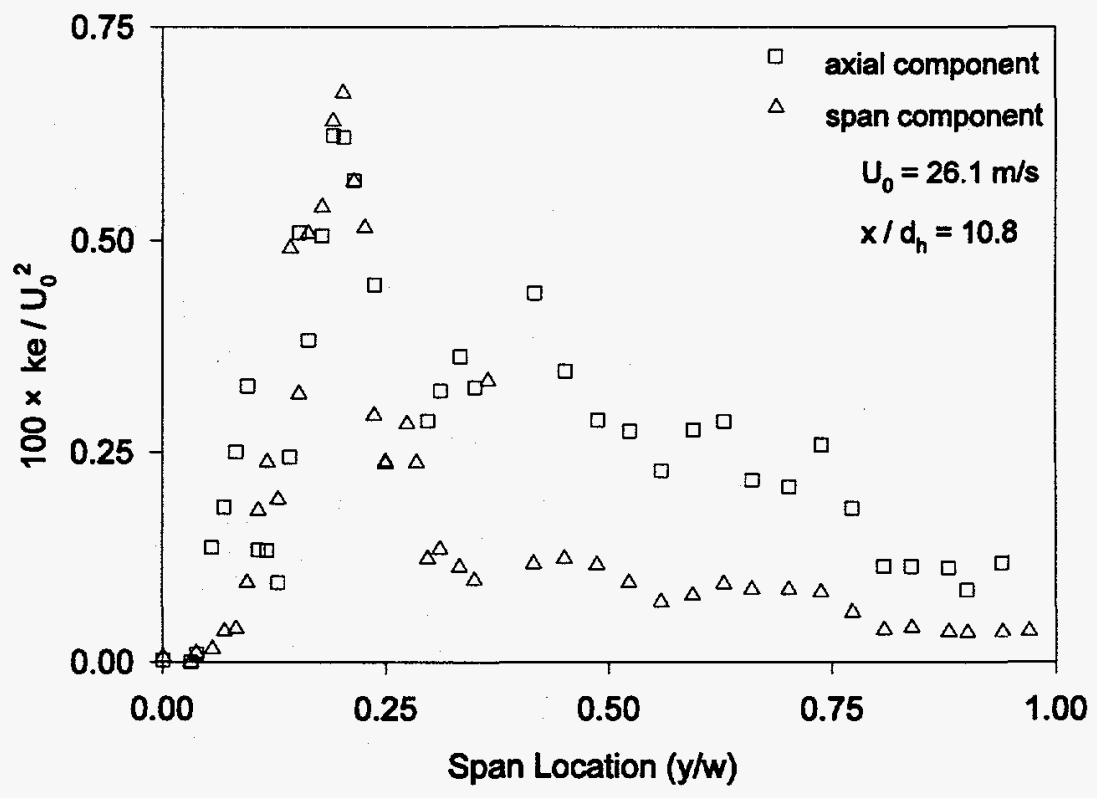

Fig. 6.5. Turbulent kinetic energy with $25 \%$ edge blockage at $\operatorname{Re}=85,000$ and $x / d_{h}=10.8$.

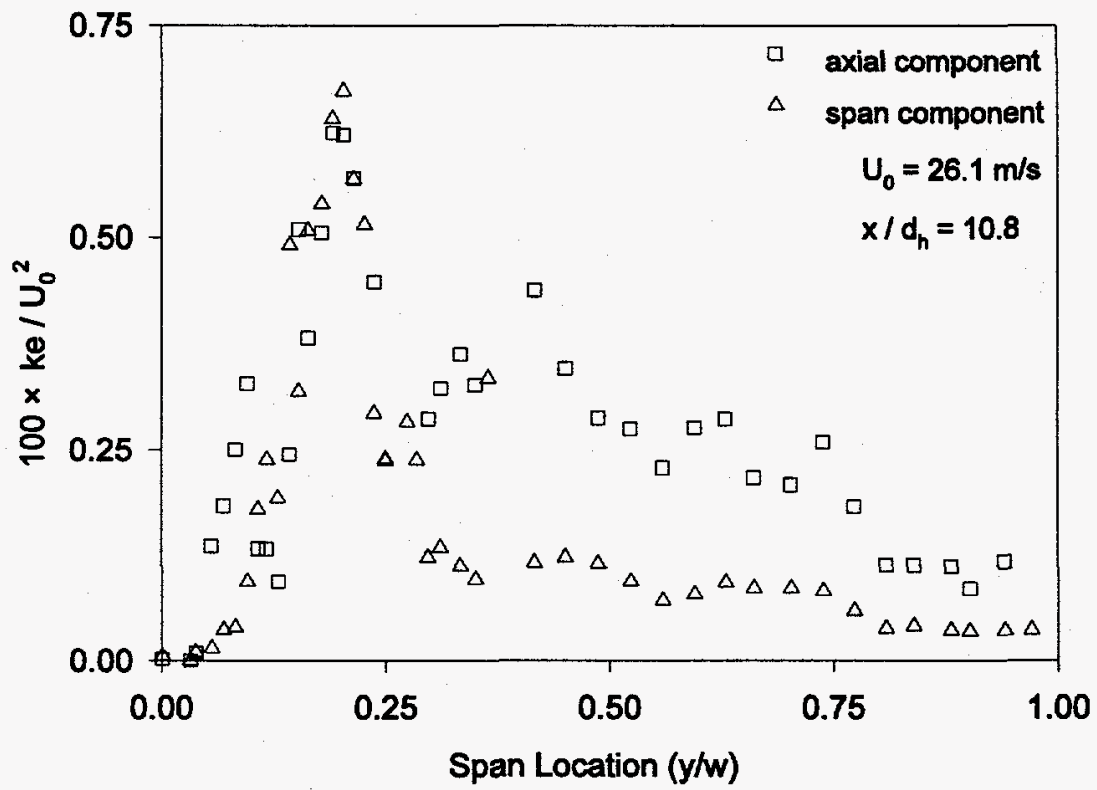

Fig. 6.6. Turbulent kinetic energy with $25 \%$ edge blockage at $\operatorname{Re}=85,000$ and $x / d_{h}=23.2$. 


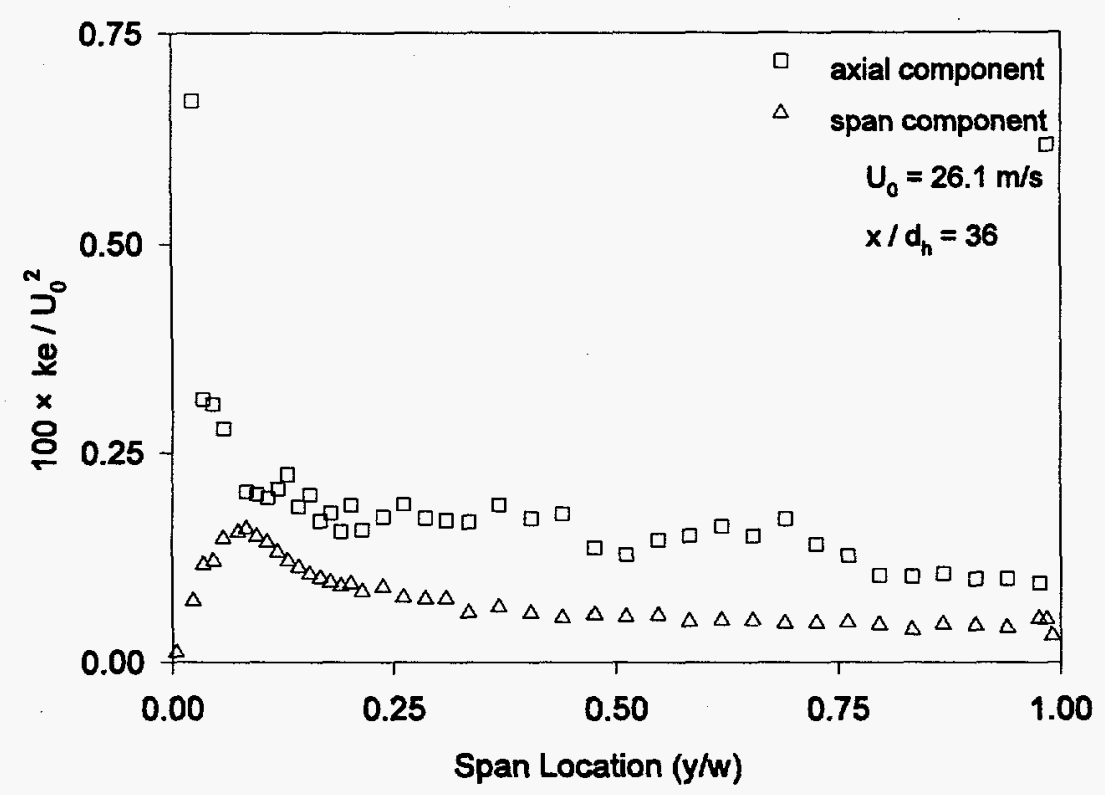

Fig. 6.7. Turbulent kinetic energy with $25 \%$ edge blockage at $R e=85,000$ and $x / d_{h}=36$.

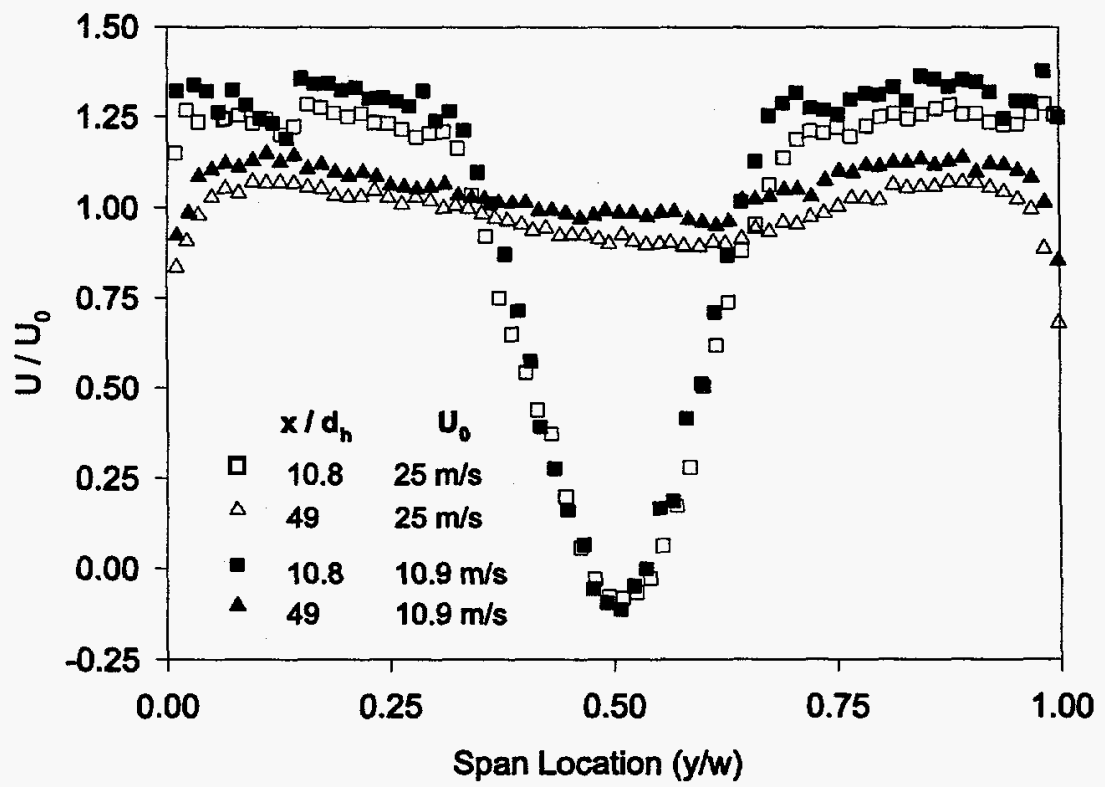

Fig. 6.8. Axial velocity profiles with $35 \%$ center blockage at $R e=35,000$ and 81,000 . 


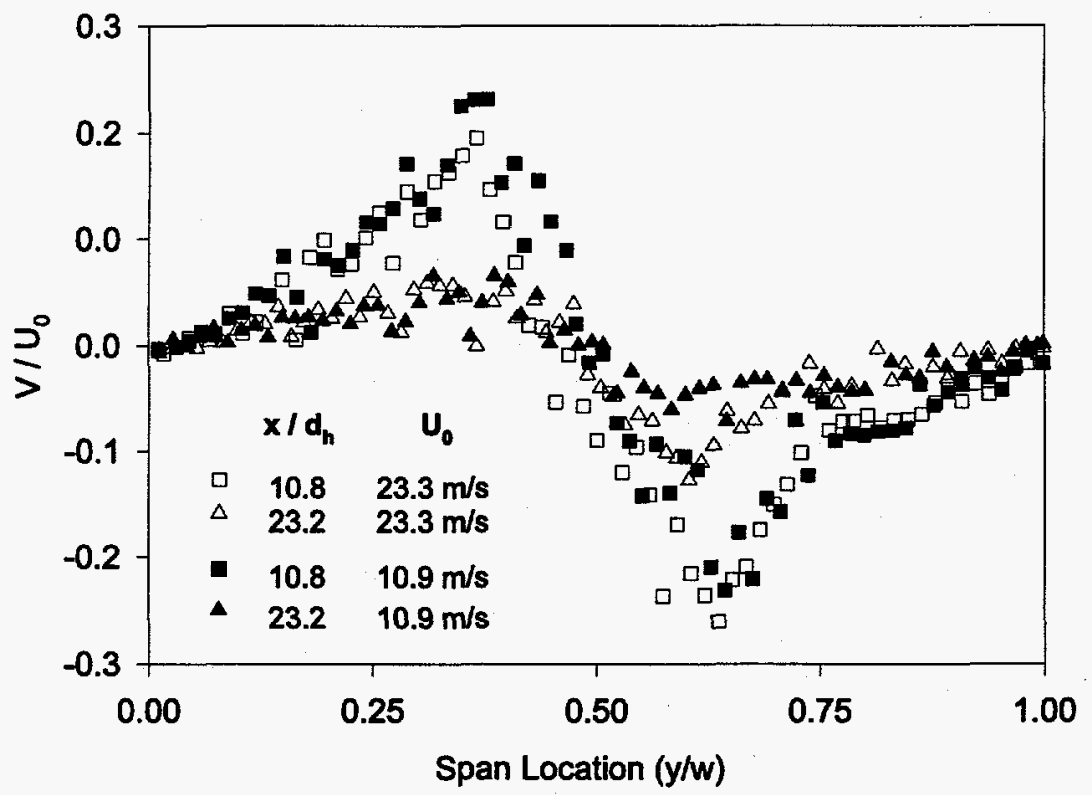

Fig. 6.9. Spanwise velocity profiles with $35 \%$ center blockage at $\operatorname{Re}=35,000$ and 76,000 .

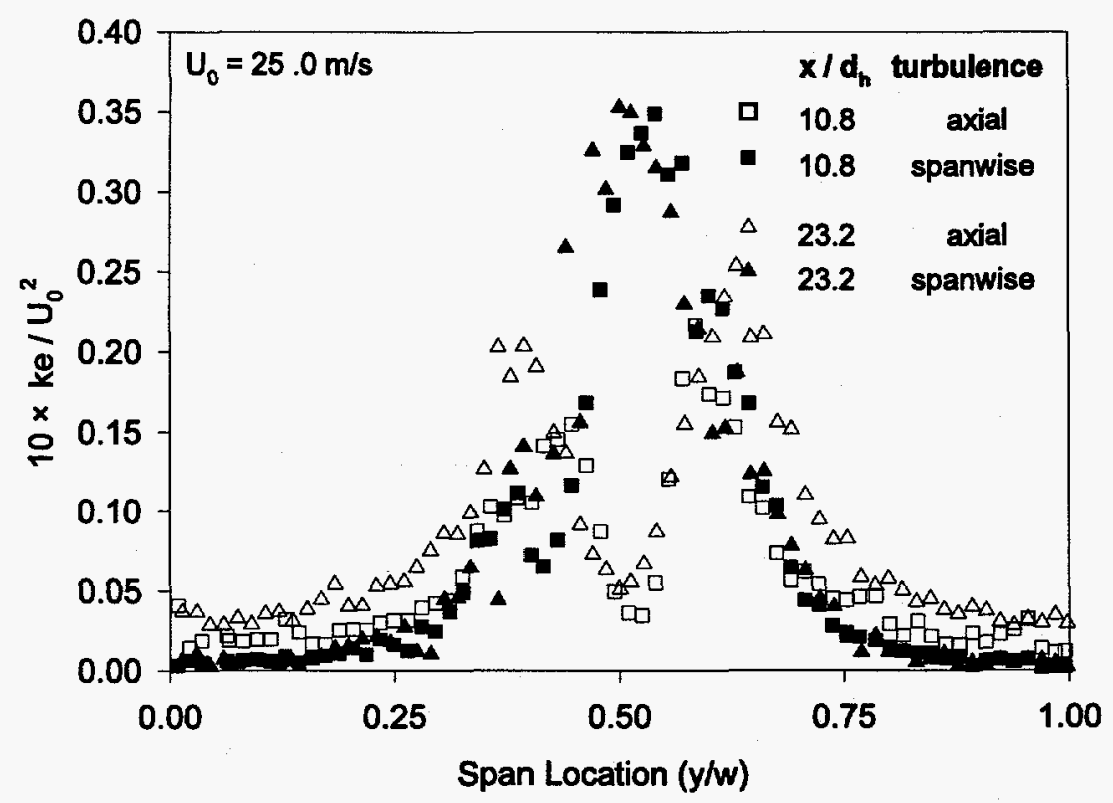

Fig. 6.10. Turbulent kinetic energy with $35 \%$ center blockage at $\operatorname{Re}=85,000$. 



\section{COMPARISON OF NUMERICAL MODELS WITH EXPERIMENTAL RESULTS}

Numerical simulations for a large number of these FBTF experiments were completed using the Fluent CFD code. There are several points at which direct comparisons are possible between the experimental results and the CFD code predictions. Velocity vectors from the CFD results for the computational nodes near the center of the gap can be compared with those measured within the LDV measurement volume. The LDV velocity vectors can also be used to help locate the boundaries of the recirculation region and the velocities within this region. Wall temperatures and heat transfer coefficients from the TLC experiments can also be compared with results from the Fluent models. Trends in turbulent kinetic energy distribution can be considered. Both the LDV data analysis and the Fluent CFD code are based on the turbulent velocity model shown in Eqs. (10) and (11).

From the TLC test for the unblocked case, the average convective heat transfer coefficient for axial locations from 15 to $35 \mathrm{~mm}\left(6\right.$ to $\left.14 \mathrm{~d}_{\mathrm{h}}\right)$ was $105 \mathrm{~kW} /\left(\mathrm{m}^{2} \cdot{ }^{\circ} \mathrm{C}\right)$ [with a standard deviation of $\left.15 \mathrm{~kW} /\left(\mathrm{m}^{2} \cdot{ }^{\circ} \mathrm{C}\right)\right]$. The CFD model for this same case also showed a heat transfer coefficient in this region of $105 \mathrm{~kW} /\left(\mathrm{m}^{2} \cdot{ }^{\circ} \mathrm{C}\right)$ and matched the total channel flow within $3 \%$.

Each TLC test with an inlet blockage showed that the region of reduced heat transfer behind the blockage had a relatively constant width over the first $34 \mathrm{~mm}$ of the channel's length, approximately equal to the width of the blockage itself. The CFD models for these tests show similar behavior. Over all these tests, the CFD models and experimental results for the total mass flow through the channel agreed within 1 to $6 \%$, indicating that the numerical method accurately emulated the pressure drops resulting from both the inlet obstruction and the channel wall friction.

The CFD models consistently predicted lower heat transfer coefficients than the TLC experimental data on the heater surface in the region behind the blockage. The average heat transfer coefficients over the heater surface were always well matched, as would be expected given the good agreement in the channel mass flow. For 10 and $25 \%$ edge blockages, the measured wall temperatures in the region behind the blockage indicated heat transfer at a rate two to four times greater than that predicted by the CFD models. After this work was completed, Fluent added an improved wall heat transfer model that is directed at providing better CFD results for separated flow regions, such as regions behind a blockage. This improved model tends to increase the heat transfer rates in such regions, providing better agreement with the TLC data.

The LDV data was also used to benchmark the CFD models. Figure 7.1 shows the axial velocity measured by the LDV and the corresponding results from the CFD model, both for a $25 \%$ edge blockage (located between $y / w=0$ and 0.25 ) and a Reynolds number of 85,000 . The recirculation region is closely matched in size and in the predicted fluid velocity within this part of the profile. The CFD model shows reattachment (the return to fully forward flow) occurring $65 \mathrm{~mm}\left(26 \mathrm{~d}_{\mathrm{h}}\right.$, or 3 times the blockage width) downstream from the channel inlet. The LDV data corroborate this location by bracketing the reattachment between windows 2 and 3, indicating an axial position between 50 and $90 \mathrm{~mm}\left(20\right.$ to $36 \mathrm{~d}_{\mathrm{h}}$, or 2 to 4 times the blockage width) down the channel. The kinetic energy terms from the LDV data for the $25 \%$ edge case were also compared with the CFD model as shown in Fig. 7.2. The isotropic RNG turbulence model in the Fluent code produces a single kinetic energy term representing the sum of the kinetic energy terms in all three dimensions. One third of this total, which ranges from 0 to $2 \mathrm{~m}^{2} / \mathrm{s}^{2}$, is therefore used for comparison to the directional LDV data. The LDV-measured axial and spanwise kinetic energy values range from 0.2 to $4.6 \mathrm{~m}^{2} / \mathrm{s}^{2}$, with the axial component about twice the spanwise kinetic energy. The CFD model matches the LDV data best in the free channel region. At the edge of the recirculation region, it estimates a smaller magnitude for the kinetic energy peak measured by the LDV.

The comparison between LDV data and CFD model predictions for the $35 \%$ central blockage at a Reynolds number of 85,000 is shown in Fig. 7.3 for a location $27 \mathrm{~mm}\left(11 \mathrm{~d}_{\mathrm{h}}\right)$ downstream from the back 


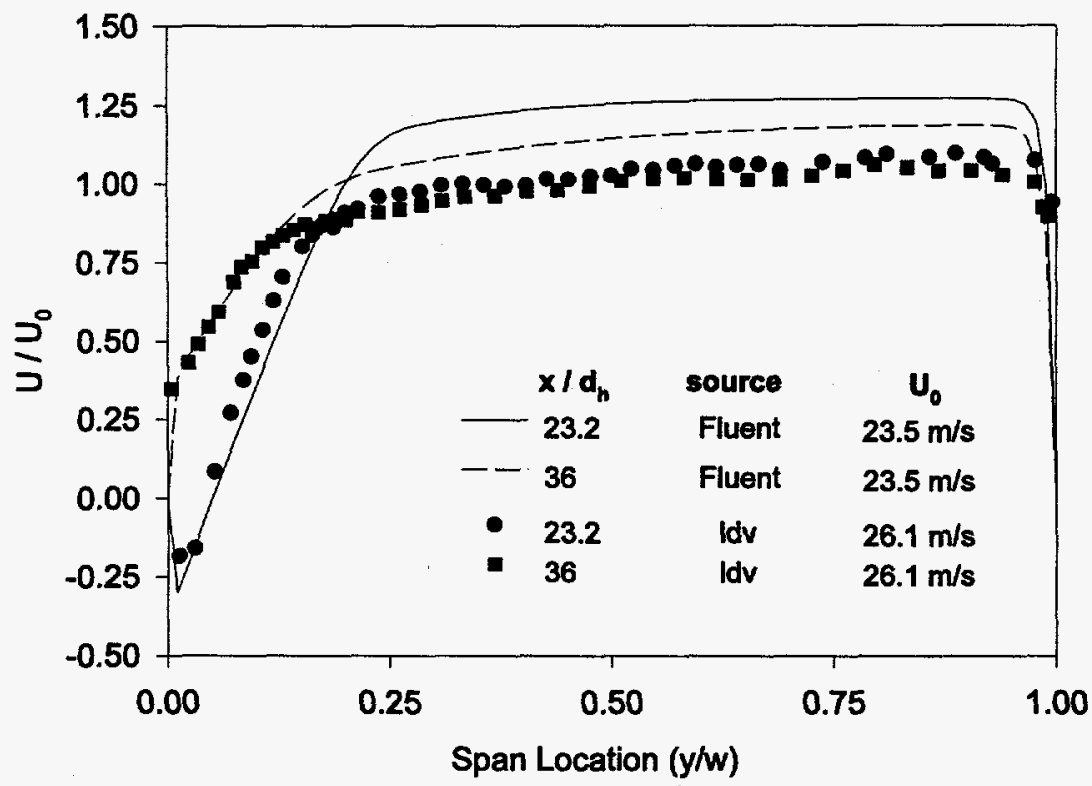

Fig. 7.1. Comparison of experimental results with CFD predictions for axial velocity profiles with $25 \%$ edge blockage at $\operatorname{Re}=85,000$.

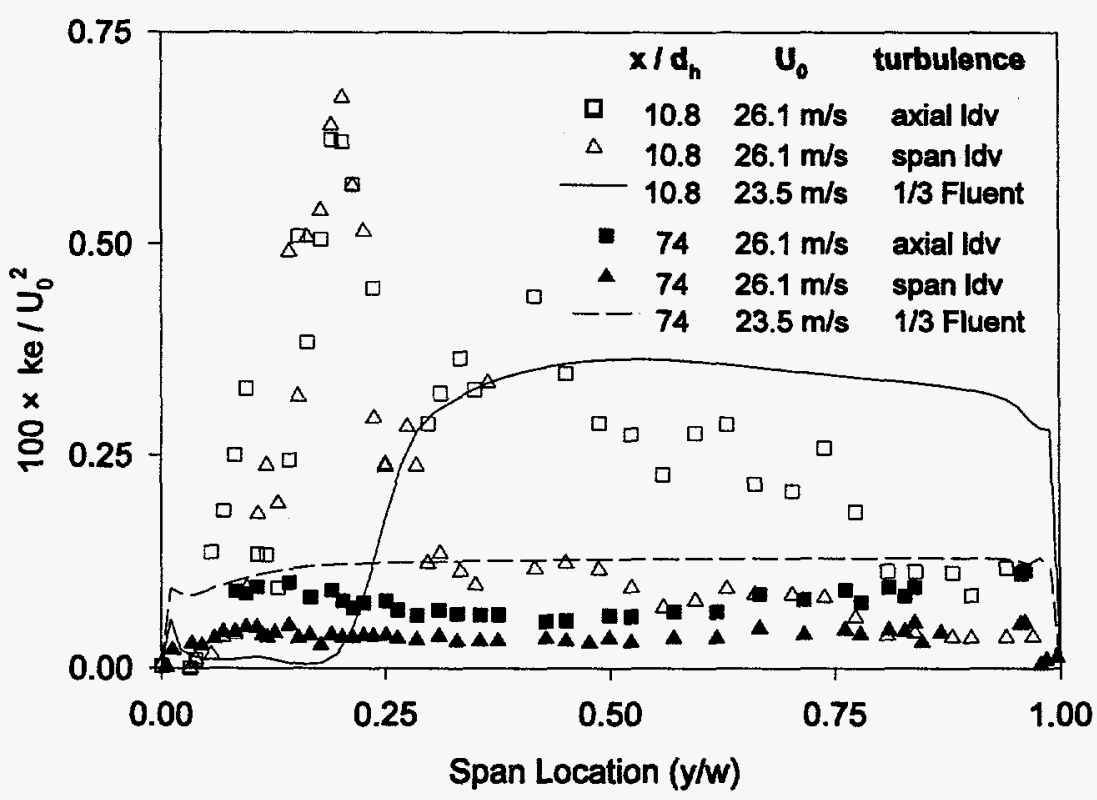

Fig. 7.2. Comparison of experimental results with CFD predictions for kinetic energy with $25 \%$ edge blockage at $\operatorname{Re}=85,000$. 


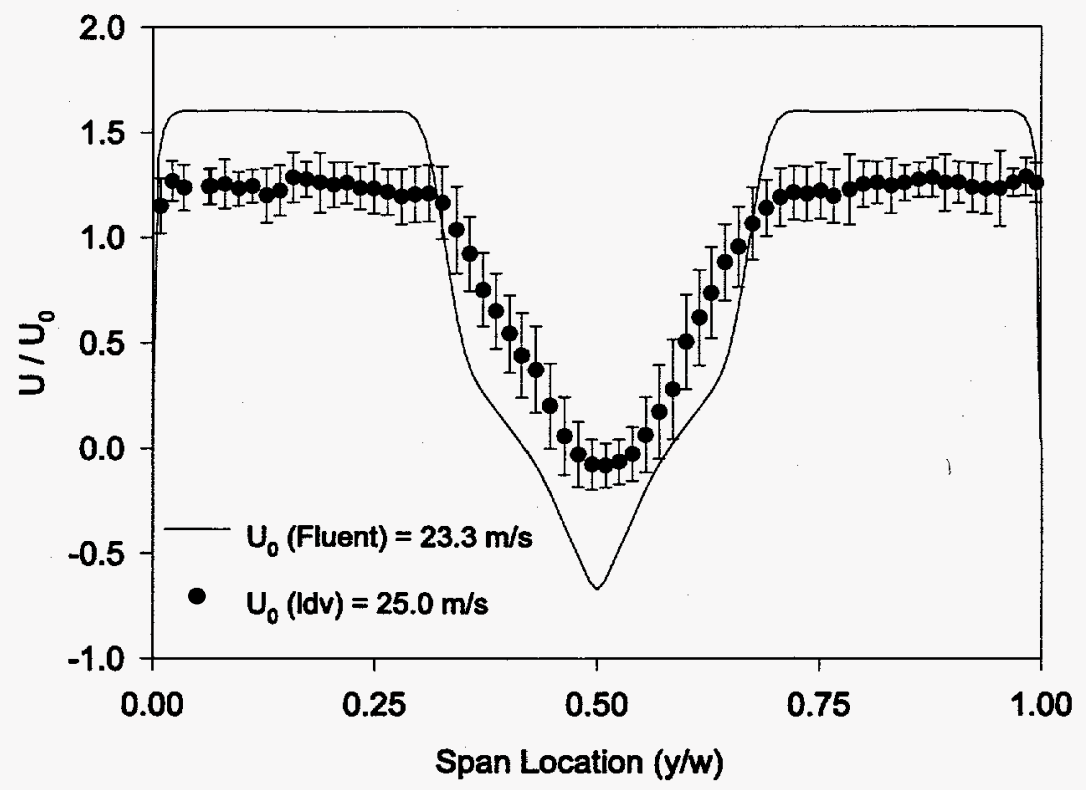

Fig. 7.3. Comparison of experimental results with CFD predictions for axial velocity with $35 \%$ center blockage at $\operatorname{Re}=85,000$.

of the blockage. Here the blockage was located from $y / w=0.325$ to 0.675 , and standard error bars are shown on the LDV data to show the range of velocities measured at each location. The larger standard errors correspond to the regions of higher turbulence near the edges of the recirculation region. The LDV data and CFD model show a similar flow pattern, although the flow is closer to recovery (less negative) in the experimental data. Indeed, the CFD model predicts a large recirculation region, about $57 \mathrm{~mm}$ long ( $23 \mathrm{~d}_{\mathrm{h}}$, or twice the blockage width), very similar to that seen for the edge blockages. The experimental data show the return to fully forward axial flow occurring in a shorter length, somewhere between 11 and $23 \mathrm{~d}_{\mathrm{h}}$.

The differences between the numerical model's prediction and the measured data were examined carefully. Experimental factors, including possible leakage, were explored as discussed previously. Several modeling factors were also considered. Working with the $35 \%$ central blockage, numerous grid refinements were made, including doubling the spanwise grid, building a more accurate model of the blockage, and refining the grid in the inlet plenum. All these model changes caused only small incremental changes to the results, the best (finest grid and most representative geometry) of which have been cited here. A time-varying model with small flow disturbances on one side of the channel was developed to investigate the possibility of shedding vortices. However, the high flow rates instead led to a general region of turbulent recirculation, and no shedding pattern was found.

The more rigorous RSM turbulence model was used to determine whether the isotropic turbulence treatment inherent in the RNG model was responsible for the differences. The RSM kinetic energy in the span and gap dimensions are almost identical. The axial kinetic energy is about twice that in the span dimension. This finding agreed with the LDV data in the free channel regions (see Fig. 6.10), but the LDV data show the spanwise turbulence greater than the axial turbulence in the center of the channel. At $11 \mathrm{~d}_{\mathrm{h}}$, both the RNG and the RSM turbulence models predicted spanwise turbulence values of about 


\section{$7-4$}

$2 \mathrm{~m}^{2} / \mathrm{s}^{2}$, compared to the LDV values ranging from less than 1 to $22 \mathrm{~m}^{2} / \mathrm{s}^{2}$. The RSM axial turbulence ranges from 1 to $7 \mathrm{~m}^{2} / \mathrm{s}^{2}$ and compares well with the LDV values ranging from about 3 to $10 \mathrm{~m}^{2} / \mathrm{s}^{2}$. The overall comparison of the RNG and RSM results showed that the RSM did a slightly better job of capturing the kinetic energy peak associated with the edge of the recirculation region and reduced the length of the recirculation region from 57 to $53 \mathrm{~mm}$. 


\section{EXTENSION OF NUMERICAL MODELS TO ADVANCED NEUTRON SOURCE OPERATING CONDITIONS}

Comparison between experimental and numerical model results are very good for edge blockages, considering the factors of velocity direction, velocity magnitude, reattachment length, and turbulent kinetic energy. The heat transfer comparison was less satisfactory, but it did show that the numerical model is conservative compared to the experimental data. The central blockage model does not match the experimental data as well as the edge model, but it does predict the appropriate flow pattern and is conservative in its prediction of the reattachment length. Both the numerical and experimental data indicate that the edge blockage presents the more limiting case for the safety evaluation because its recirculation region is much longer than that for the central blockage. Based on these benchmarking comparisons for water at room temperature and with little or no wall heat flux, the numerical models were then extended to model those aspects of ANS operating conditions that are difficult to test experimentally.

Two of the most important differences between the FBTF test conditions and ANS operating conditions are the high wall heat flux and power distribution and the temperature-dependent fluid properties of $\mathrm{D}_{2} \mathrm{O}$ expected in the actual reactor. A simple, two-dimensional model of the unblocked channel was developed to test the ability of the CFD model to capture the effects of these two changes. A piecewise linear approximation (using 20 data points) for each fluid property was incorporated into the CFD model based on correlations developed for the ANS project. ${ }^{4}$ This simplified model used a constant wall heat flux of $6 \mathrm{MW} / \mathrm{m}^{2}$. The results closely matched the design data, showing the expected increase in Reynolds number at the channel exit resulting from the increased velocity of the hotter, less dense fluid.

The heat flux on the fuel plate surface is not constant, but varies with position and time. A "worstcase" heat flux, shown in Fig. 8.1, was selected from the neutronics analysis and patched into the threedimensional numerical model as a wall boundary condition for several edge blockage cases. Temperaturedependent fluid properties were used for all of these models. These cases included 10, 12, and 25\% (8.4-, $10-$, and $21-\mathrm{mm}$ ) edge blockages with unheated entrance lengths of 4 and 20 hydraulic diameters (10 and $50 \mathrm{~mm}$ ).

There are several ways to define "survivable" blockage events. All design calculations were based on single-phase flow; i.e., vapor generation was equated to fuel plate failure. Boiling was assumed conservatively to occur whenever the wall temperature was greater than the saturation temperature for the local pressure. Figures 8.2 and 8.3 show results for a case with a $25 \%$ edge blockage, variable $\mathrm{D}_{2} \mathrm{O}$ properties, and the wall heat flux shown in Fig. 8.1. Figure 8.2 shows that unacceptable wall temperatures are predicted even with a $50-\mathrm{mm}$ unheated entrance length. Figure 8.3 shows the velocity vectors of the fluid near the channel wall in the recirculation region. When similar models were made for both 10 and $12 \%$ blockage sizes, they showed acceptable wall surface temperatures for the same wall heat flux pattern. 


$1.05 E+07$
$9.93 E+06$
$9.40 E+06$
$8.88 E+06$
$8.36 E+06$
$7.83 E+06$
$7.31 E+06$
$6.78 E+06$
$6.26 E+06$
$5.74 E+\infty 6$
$5.21 E+06$
$4.69 E+06$
$4.16 E+06$
$3.64 E+06$
$3.11 E+06$
$2.59 E+06$
$2.07 E+06$
$1.54 E+06$
$1.02 E+06$
$4.93 E+05$
$-3.10 E+04$

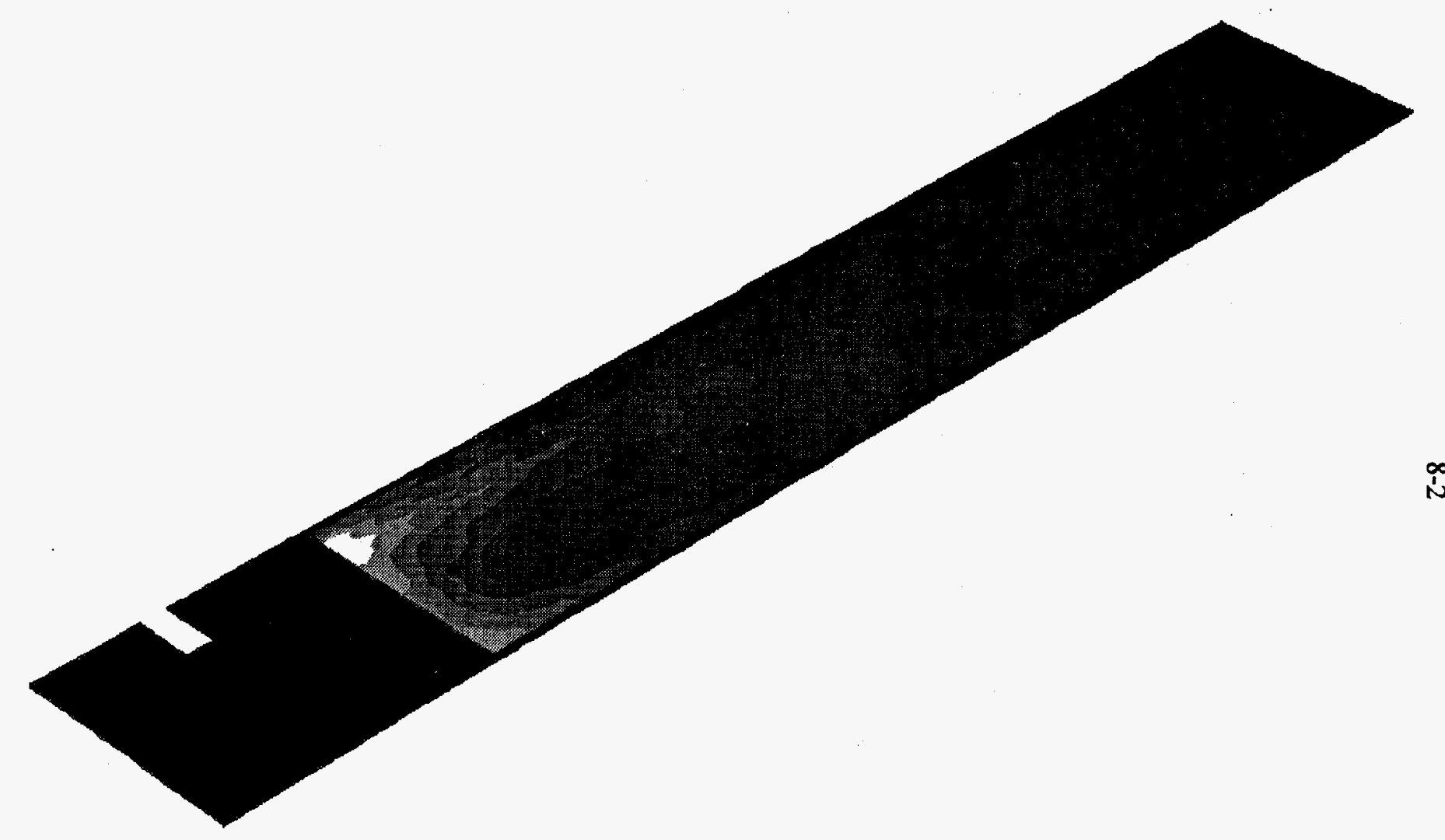

Fig. 8.1. "Worst-case" heat flux (in $W / \mathrm{m}^{2}$ ) imposed on channel wall. 
$6.01 E+02$

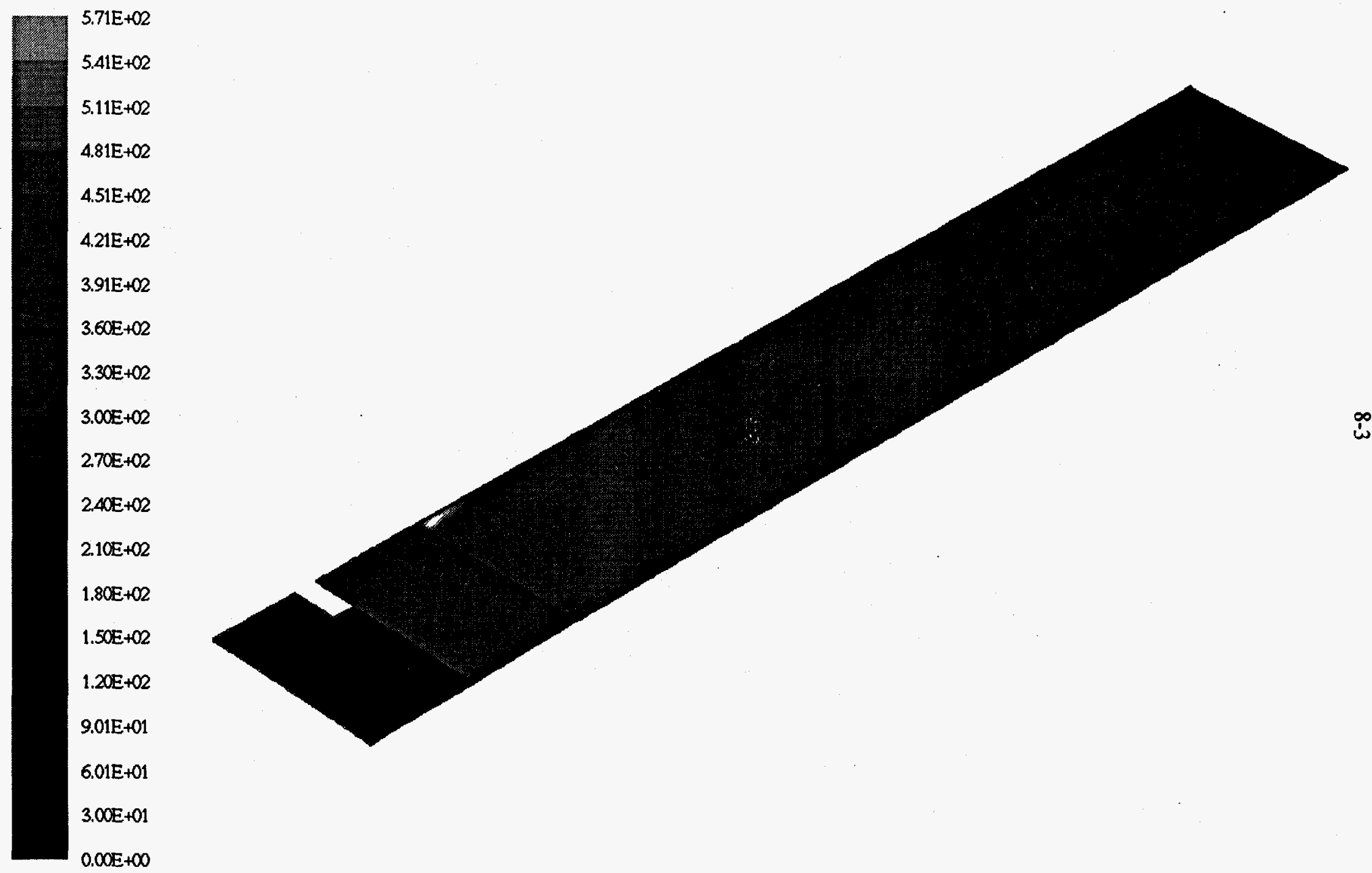

Fig. 8.2. Wall temperature (in $\mathrm{K}$ ) for "worst-case" heat flux with 50 -mm unheated entrance and $25 \%$ edge blockage. 


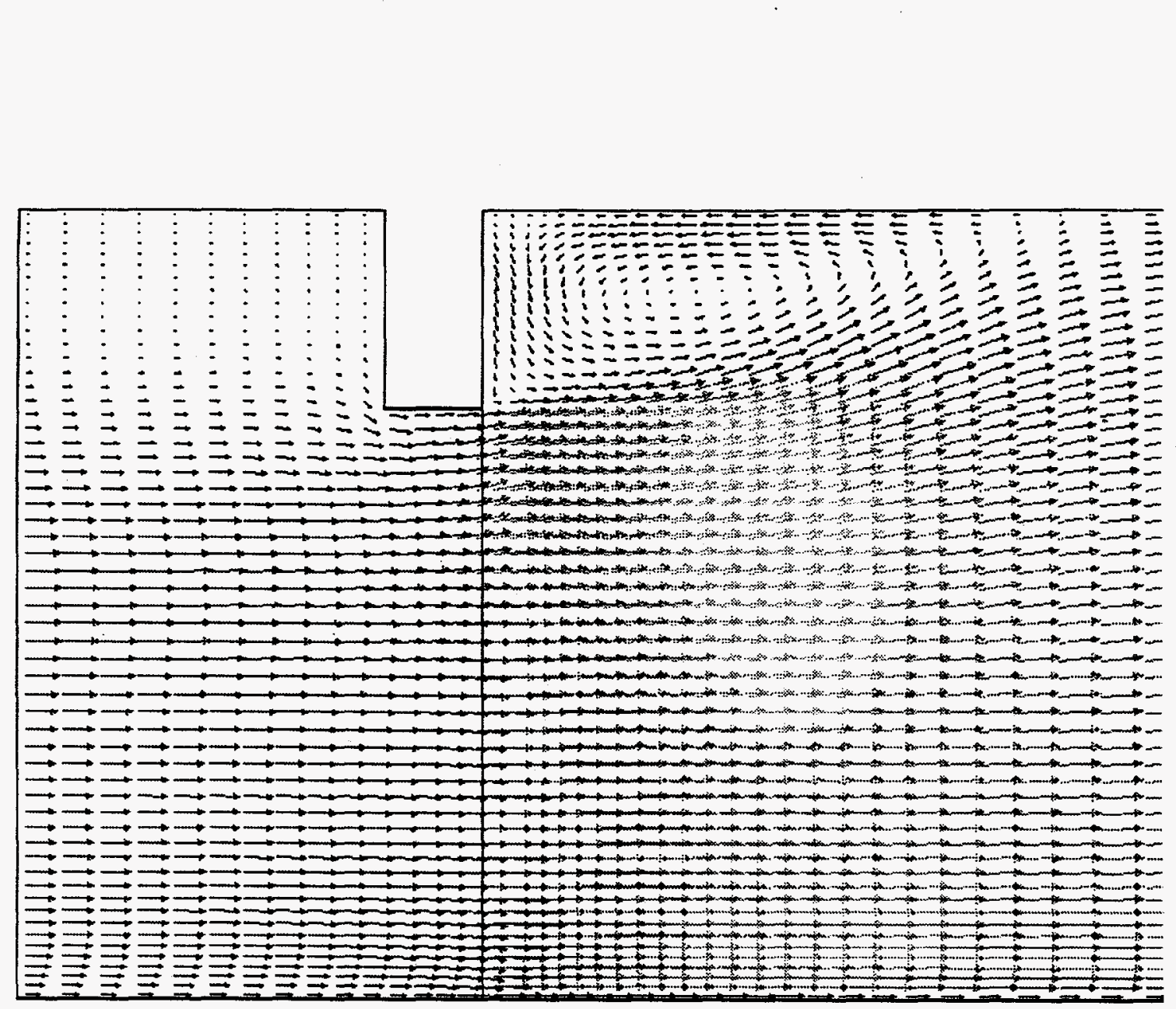




\section{CONCLUSIONS}

Extrapolation from existing data in the literature indicated a need for further evaluation of potential entrance blockages for the ANS core. This same preliminary effort determined that an experimental program would be required to provide a suitable foundation for analysis based on available CFD tools. The early efforts also focused attention on the proper choice of a turbulence model for the separated flow patterns expected behind a partial entrance blockage.

The experimental program included the application of two measurement techniques for measuring the downstream effects of entrance blockages. Thermochromic liquid crystals were used to measure wall temperatures on a diagnostic heater, and a laser doppler velocimeter system was employed to measure spanwise and axial velocity profiles and associated turbulence parameters.

Comparison of experimental data and CFD results for edge blockage cases shows that the CFD models are accurate in their representation of the fluid velocity vectors and provide a conservative estimate of heat transfer behind the blockage. Both experimental data and CFD models show the edge case to have the longer recirculation region, making the well-benchmarked edge blockage the limiting case for any safety analysis. Given this careful validation of the FBTF edge blockage models, extension of these models to incorporate variations in wall heat flux and temperature-dependent fluid properties is reasonable. To date, these expanded models have shown that blockage sizes up to $10 \mathrm{~mm}$ will not cause damage to the fuel plates if the unheated entrance region is at least $50 \mathrm{~mm}$ long. However, these results are based on a single wall heat flux pattern, and caution must be used until further parametric evaluations of this factor are complete. Other results from the empirical data and modeling evaluation show that blockage elements equal to $25 \%$ of the channel span would create a region of reduced velocity, and therefore reduced heat transfer, extending about six times the blockage width. The data from this experimental program will be preserved for future use in examining flow phenomena within thin, rectangular channels. 


\section{REFERENCES}

1. E. M. Sparrow and N. Cur, "Maldistributed Inlet Flow Effects on Turbulent Heat Transfer and Pressure Drop in a Flat Rectangular Duct," J. Heat Transfer 105, 527-35 (August 1983).

2. N. Cur, "Local Turbulent Heat Transfer Coefficients in a Symmetrically or Asymmetrically Heated Flat Rectangular Duct with Either Uniform or Nonuniform Inlet Velocity," Ph.D. thesis, University of Minnesota, Minneapolis, 1982.

3. J. P. Holman, Heat Transfer, 4th ed., McGraw Hill, New York, 1976.

4. J. A. Crabtree and M. Siman-Tov, Thermophysical Properties of Saturated Light and Heavy Water for Advanced Neutron Source Application, ORNL/TM-12322, Martin Marietta Energy Systems, Inc., Oak Ridge Natl. Lab., May 1993.

5. J. A. Crabtree, "Use of Image Processing Techniques for Heat Transfer Measurements Using Thermochromatic Liquid Crystals," pp. 27-33 in Optimal Design of Thermal Systems and Components, HTD Vol. 279, ed. L. A. Haas and R. S. Downing, American Society of Mechanical Engineers, New York, 1994.

6. TSI, Inc., Flow Information Display (FIND) Software, Version 4.0, St. Paul, Minn., March 1993.

7. R. M. Lueptow, "Software for Computational Fluid Flow and Heat Transfer Analysis," Comput. Mech. Eng. 6, 10-17 (March/April 1988).

8. Fluent, Inc., Fluent User's Guide, Version 4.2, Lebanon, N.H., June 1993.

9. J. E. Meyer, S. M. Kwak, and T. D. Shubert, Narrow Channel Turbulence Modeling Project Final Report, MITNE-299, Massachusetts Institute of Technology, Cambridge, March 1992.

10. Flow Science, Inc., Computational Modeling Power for Scientists and Engineers, FLOW-3D User's Manual, FSI-91-00-1, Los Alamos, N.M., 1991.

11. D. Choudhury, S.-E. Kim, and W. S. Flannery, "Calculation of Turbulent Separated Flows Using a Renormalization Group Based k- $\epsilon$ Turbulence Model," pp. 177-87 in Separated Flows, FED Vol. 149, American Society of Mechanical Engineers, New York, 1993. 


\section{INTERNAL DISTRIBUTION}

1. R. Beaty

2. T. Burchell

3-7. J. H. Campbell

8. N. C. J. Chen

9. D. Cook

10-14. A. Crabtree

15. W. G. Craddick

16. G. Farquharson

17-21. D. K. Felde

22. R. M. Harrington

23. R. L. Johnson

24. J. A. March-Leuba

25. D. G. Morris

26-30. J. E. Park

31. R. B. Rothrock
32. D. L. Selby

33. M. Siman-Tov

34-38. T. K. Stovall

39. R. P. Taleyarkhan

40. M. W. Wendel

41. C. D. West

42. G. T. Yahr

43. G. L. Yoder

44. ORNL Patent Office

45-46. Central Research Library, Document Reference Section

47. $Y-12$ Technical Library

48-49. Laboratory Record Dept.

50. Laboratory Records, RC

\section{EXTERNAL DISTRIBUTION}

51. L. Y. Cheng, Brookhaven National Laboratory, Upton, NY 11973

52. R. Harvill, 1611 Laurel Ave., Knoxville, TN 37916

53. A. E. Ruggles, University of Tennessee, College of Engineering, Pasqua Nuclear Engineering Building, Knoxville, TN 37966

54. J. M. Ryskamp, Idaho National Engineering Laboratory, P.O. Box 1625, Idaho Falls, ID 83415-3885

55. U.S. Department of Energy, ANS Project Office, Oak Ridge Operations Office, FEDC, MS-8218, P.O. Box 2009, Oak Ridge, TN 37831-8218.

56-57. Office of Scientific and Technical Information, P.O. Box 63, Oak Ridge, TN 37831. 
